\title{
Synthesis and Characterization of Porous Magnetite Nanosphere Iron Oxide as a Novel Adsorbent of Anionic Dyes Removal from Aqueous Solution
}

\author{
Mohamed G. El-Desouky 1,* (D), Nader Hassan 2 ${ }^{\text {(D) }, \text { Ahmed Shahat }}{ }^{3}$ (D), Akram El-Didamony ${ }^{4}$ (D) , Ashraf \\ A. El-Bindary 5 (iD
}

1 Egyptian propylene and polypropylene company, Port Said 42511, Egypt; ch.moh.gamal@ gmail.com (M.G.E-D.);

2 Chemistry Department, Faculty of Science, Port Said University, Port Said 42511, Egypt; nader_yousri1972@yahoo.com (N.H.);

3 Chemistry Department, Faculty of Science, Suez University, Suez 43518, Egypt; ashahat@ aucegypt.edu (A.S.);

4 Chemistry Department, Faculty of Science, Zagazig University, Zagazig 44519, Egypt; ak_eldidamony @ yahoo.com (A.ED.);

5 Chemistry Department, Faculty of Science, Damietta University, Damietta, Egypt; abindary @ yahoo.com (A.A.E-B.);

* Correspondence: ch.moh.gamal@gmail.com (M.G.E-D.)

Received: 5.01.2021; Revised: 2.02.2021; Accepted: 4.02.2021; Published: 9.02.2021

\begin{abstract}
Porous magnetite $\mathrm{Fe}_{3} \mathrm{O}_{4}$ nanospheres (PMNs) are synthesized for removal from an aqueous solution of anionic dyes Acid Red 57 (AR57) and Remazol Red (RR) and are used as a highperformance adsorbent. Characterization of PMNs was carried out using various techniques, such as Fourier-transform infrared spectroscopy, the surface area measured by Brunauer Emmett-Teller (BET), and it was found $143.65 \mathrm{~m}^{2} \mathrm{~g}^{-1}$, and were spherical-shaped as determined by TEM. Surface modification was calculated using electron microscopy (SEM) scanning. The spherical morphology of the PMNs is very uniform, with an average particle size of $\sim 25,84 \mathrm{~nm}$ in diameter. Variables such as initial $\mathrm{pH}$, the dosage of adsorbent, contact time, and temperature were analyzed to find the optimal adsorption conditions for extracting Acid Red 57 (AR57) and Remazol Red (RR) from aqueous solutions. For respective AR57 and $\mathrm{RR}$, the optimal $\mathrm{pH}$ for the extraction of the anionic dyes examined from water solutions was 3 and 4. The maximum adsorption potential expected for AR57 and RR dyes was 888.68 and $808.43 \mathrm{mgg}^{-1}$, respectively. The effects of the initial solution $\mathrm{pH}$, temperature, initial concentration, contact time, salinity, and dosing of PMNs were systematically analyzed. These dyes were suitable for acid $\mathrm{pH}$ adsorption, as the PMNs Zero-charge point ( $\mathrm{pH}_{\mathrm{PZC}}$ ) equals 4.3. Adsorption findings were based on the Langmuir, Freundlich, Dubinin - Radushkevich, and Temkin adsorption isotherms. The adsorption isotherm had been found to follow the Langmuir model for both dyes. The mean adsorption energy $\left(E_{a}\right)$ is 20.24 and $31.3 \mathrm{kJmol}-1$ for AR57 and RR, respectively, indicating a chemisorption process. The adsorption kinetics had been found to follow the pseudo-second-order kinetic model. The adsorption process was verified to be endothermic and spontaneous by thermodynamic studies. Using ethanol as a solvent, it was also studied the process of desorption of the adsorbed anionic dyes.
\end{abstract}

Keywords: PMNs; pH PZC; adsorption isotherm; thermodynamics.

(C) 2021 by the authors. This article is an open-access article distributed under the terms and conditions of the Creative Commons Attribution (CC BY) license (https://creativecommons.org/licenses/by/4.0/).

\section{Introduction}

Despite a big issue: water contamination, rivers, seas, and lakes become more and more water-disposed. One of the water contaminants that has gained much attention is an organic 
dye, due to its toxic nature and harmful effects on all life types [1]. Dyeing factories are one of the major sources of pollution from the atmosphere because the heavily colored waste discharged colorants are resistant to light, other chemicals, oxidizing agents and due to their chemical composition are biologically non-degradable and thus, once released into the aquatic environment, it is difficult to remove [2]. Removal of this colored water into receiving waters may affect aquatic life [3,4].

Owing to economic considerations such as ultrafiltration, coagulation, oxidation, ozonation, reverse osmosis, sedimentation, flotation, precipitation, and so on, modern wastewater treatment systems are complicated to use in the treatment of textile dyes[5]. Recent years have seen the removal of pollutants by adsorption become more common. Thanks to the demonstrated efficiency of changing waste to stable forms than the traditional treatment methods mentioned above [6,7].

Porous magnetite nanoparticles $\left(\mathrm{Fe}_{3} \mathrm{O}_{4}\right)$, as a result of their attractive potential applications as an interesting class of crystalline materials, have provided great agreement of consideration [8]. The size and shape-controlled synthesis of nano-scaled magnetite has been of considerable interest recently $[9,10]$.

PMNs were synthesized and described in this study, and the adsorption activity of AR 57 and RR was analyzed in detail[11]. Parameters influencing the adsorption cycle, such as initial dyes concentration, solution $\mathrm{pH}$, the dosage of PMNs, temperature, and contact time, were examined. Isotherm and kinetic simulations analyzed the experimental equilibrium adsorption data [12-14].

\section{Materials and methods}

\subsection{Chemicals.}

Chemicals were used as obtained without additional purification process. They include ammonium ferrous sulfate (99\%, Tianjin Kemiou Chemical Reagent, China), 2methylimidazole (Hmim) (Sinopharm chemical reagent Co. Ltd., China), anhydrous ethanol (99.7\%, Sinopharm chemical reagent Co. Ltd., China), Acid Red 57 and Remazaol Red were purchased from Merck KGaA, 64271 Darmstadt, Germany.

\subsection{Preparation of porous magnetite nanoparticles (PMNs).}

Porous magnetite nanoparticles were prepared by weighing about $1.67 \mathrm{gm}$ from 2methyl imidazole and dissolve it in 20.75 methanol, stirring well for 10 min until completely dissolved (solution 1). About $3.9 \mathrm{gm}$ from ferrous ammonium sulfate were weighed and dissolved in a suitable amount of distilled water (about $25 \mathrm{ml}$ ), stirring well for $10 \mathrm{~min}$ until completely dissolved (solution 2). A dark brown suspension solution was formed after adding solution 2 to solution 1, then stirring well for $15 \mathrm{~min}$. The solution was poured into a clean bottle and put in ultrasonic at $50{ }^{\circ} \mathrm{C}$ for $15 \mathrm{~min}$ to decrease the particle size of PMNs. The solution was filtered, and the precipitate was dried in the oven at $60{ }^{\circ} \mathrm{C}$ for 6 hours until completely dry $[15,16]$.

\subsection{Preparation of Adsorbate.}

A stock solution $\left(1 \times 10^{-3} \mathrm{M}\right)$ of AR57 and RR were prepared individually. We used bidistilled water in preparing the stock solutions and during all experimental analysis. 
Table 1. Adsorbate (Acid Red 57 and Remazol red) properties utilized in the study.

\begin{tabular}{|c|c|c|c|c|}
\hline Dye & Ball and stick model of dye & $\begin{array}{c}\text { Molar mass } \\
\left(\text { g.mol }^{-1}\right)\end{array}$ & $\lambda_{\max }$ & $\begin{array}{c}\text { Electrical } \\
\text { property }\end{array}$ \\
\hline Acid Red 57 & & 548.57 & 512 & Anionic \\
\hline Remazol Red & & 562.58 & 541 & Anionic \\
\hline
\end{tabular}

\subsection{Characterization of PMNs.}

With a JASCO-FT/IR-4100 spectrometer (Jasco, Easton, MD, USA), FTIR analysis was carried out in the wavenumber range $400-4000 \mathrm{~cm}^{-1}$ the finely ground sample of PMNs was involved into $\mathrm{KBr}$ discs before analysis. By X-ray diffraction (XRD) system structural deviations of the as-prepared PMNs samples was investigated a Shimadzu XRD-6000 diffract meter (Shimadzu Corporation, Tokyo, Japan) equipped with $\mathrm{Cu} \mathrm{K \alpha}$ radiation $(\lambda=1.54 \AA$ ). The $2 \theta$ range was varied between $5-80^{\circ}$ at a scanning rate of $0.02^{\circ}$. We measured and optimized space group and lattice parameters of the crystal system by using CRYSFIRE and CHEKCELL computer databases. The samples' morphologies and structures were characterized by transmission electron microscopy (TEM, FEI Teanci G2 F20, USA). UV-visible spectrophotometer (HACH LANGE DR5000) was based on sample absorbance measurements using $1.0 \mathrm{~cm}$ quartz cell. $\mathrm{N}_{2}$ sorption isotherms were recorded at the boiling temperature of liquid nitrogen $\left(-196^{\circ} \mathrm{C}\right)$ on ASAP 2020 (Micrometrics, USA). The particles were exposed to a vacuum $(5 \times 10-3$ torr $)$ at $200{ }^{\circ} \mathrm{C}$ before analysis to ensure a clean surface. Using the Brunauer-Emmett-Teller (BET) method, from which the surface area of Brunauer-EmmettTeller (BET) and pore volume of Barrett-Joyner-Halenda (BJH) were determined. A scanning electron microscope (SEM) was used to study the surface morphology of PMNs investigation was at speeding up voltages of $20 \mathrm{kV}$ (JEOL-JSM-6510 LV) using gold coating examination. HANNA instrument $\mathrm{pH}$ meter (model 211) was used for $\mathrm{pH}$ modification.

\subsection{Experimental Design for Batch Adsorption Studies.}

Experiment parameters such as $\mathrm{pH}$ value $(2-12)$, A stock solution $\left(1 \times 10^{-3} \mathrm{molL}^{-1}\right)$ of Acid Red 57 (AR57) and Remazol Red (RR) dye was prepared by dissolving an appropriate quantity of the powder in distilled water. Dose concentration of sorbent (PMNs) (0.01 to 0.1) g $25 \mathrm{~mL}^{-1}$, adsorbent dosage, and temperature $\left(25-55^{\circ} \mathrm{C}\right)$ on the adsorption of AR57 and RR in aqueous solution were investigated in detail [17]. After agitation at $200 \mathrm{rpm}$ for $120 \mathrm{~min}$, the adsorbent was separated by the magnet [17] (Figure 2). The concentration of dyes was determined by UV-vis at 512 and $541 \mathrm{~nm}$ for AR57 and RR, respectively [18,19]. 
Percentage of dye removal (R) was calculated using Eq. (1):

$$
\% \mathrm{R}=\frac{\left(C_{0}-C_{t}\right)}{C_{0}} \times 100
$$

While the sorption capacity $\left(q_{\mathrm{e}}, \mathrm{mmolg}^{-1}\right)$ was determined by the mass balance equation (Eq. 2):

$$
\mathrm{qe}=\frac{\left(C_{0}-C_{e}\right) V}{M}
$$

The sorbet amount of dye per unit weight of the sorbent at time $t\left(q \mathrm{t}, \mathrm{mmolg}^{-1}\right)$ was calculated from the mass balance equation (taking into account the decrement in the volume of the solution) as follows (Eq. 3):

$$
\mathrm{q}(\mathrm{t})=\sum_{\mathrm{i}=1}^{\mathrm{n}} \frac{\left[\mathrm{C}(\mathrm{t})_{(\mathrm{i}-1)}-\mathrm{C}(\mathrm{t})_{(\mathrm{i})} \mathrm{V}(\mathrm{t})_{(\mathrm{i}-1)}\right]}{\mathrm{M}}
$$

where $C(t)_{(i)}\left(\mathrm{molL}^{-1}\right)$ is the dye concentration of the withdrawn sample number $i$ at time $t$, $C(t)_{(0)}=C_{0}, V(t)_{(i)}(\mathrm{mL})$ is the volume of the solution in the flask at sample number $i$ and time $t$, and $M$ is the mass of the sorbent in the flask. Here, $V(t)_{(i)}-V(t)_{(i-1)}=1 \mathrm{~mL}$ (the sample volume).

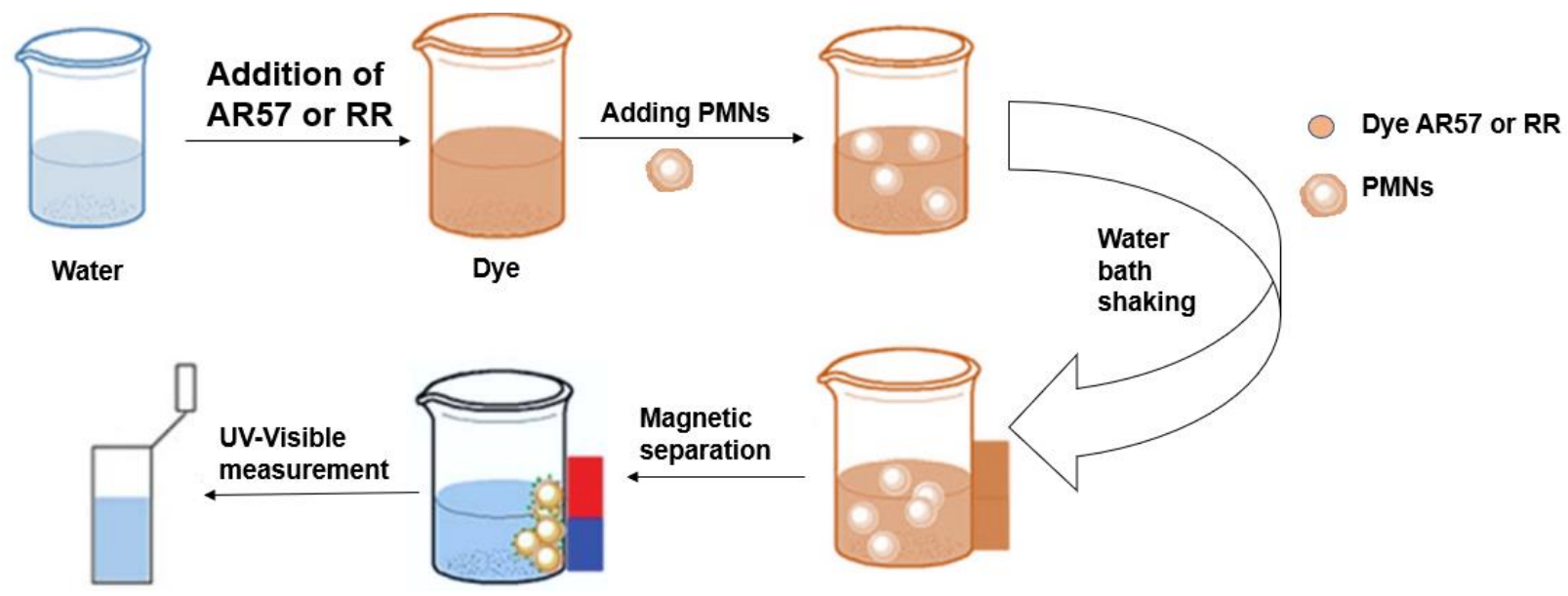

Figure 1. Schematic illustration of the adsorption process for the Acid red 57 (AR57) and Remazol red (RR) using $\mathrm{Fe}_{3} \mathrm{O}_{4}$.

\section{Results and discussion}

\subsection{Characterization of PMNs.}

3.1.1 X-ray diffraction (XRD) patterns.

PMNs pattern XRD appears in Fig.2. The samples can be assigned to PMNs in keeping with the XRD pattern, and no alternative element has been discovered in those samples [2022]. The occurrence of strong peaks at $2 \theta=30.45^{\circ}, 35.765^{\circ}, 36.94^{\circ}, 43.46^{\circ}, 53.94^{\circ}, 57.485^{\circ}$, $63.09^{\circ}$ and $74.7^{\circ}$ match to planes (200), (311), (222), (400), (422), (511), (400), and (533), respectively. That shows the high crystallinity of the PMNs prepared. The XRD analysis on the prepared PMNs is relatively compatible with the $\mathrm{Fe}_{3} \mathrm{O}_{4}$ standardized cubic spinel figures (JCPDS card no. 19-0629). No additional peaks are detected which fit into other phases, representing high purity and good sample crystallinity. 
Because of the peak locations and intensity ratios, a polycrystalline design of the $\mathrm{Fe}_{3} \mathrm{O}_{4}$ nanoparticles was suggested [23]. Scherrer formula was used to calculate the size of PMNs nanoparticles in crystallite (Eq. 4):

$$
\mathrm{D}=\frac{K \lambda}{\beta \cos \theta}
$$

where $\lambda$ is the wavelength of the X-ray $(1,54 \AA), \beta$ is the angular width of the peak at half its maximum intensity (full width at half maximum) corrected for instrumental expansion, $\beta$ is the limit of the Bragg diffraction rate, and $\mathrm{K}$ is the Scherrer constant $(0,9 \AA)$. The crystallite size of PMNs measured at the height of the high-intensity peak at $2 \theta=35^{\circ}$ was $30.05 \mathrm{~nm}$. Since the magnetite $(\mathrm{PMN})$ and magnetite $\left(\mathrm{Fe}_{3} \mathrm{O}_{4}\right)$ XRD patterns are very similar, it is important to calculate the interplanar distance $\mathrm{d}$ and the lattice parameter to distinguish between the two phases[24]. The interplanar spacing $d$ and the lattice parameter for the reflected peak (311) were calculated using the following equations (Eq. 5 and 6):

$$
\begin{aligned}
& 2 d_{h k i} \sin \theta=n \lambda \\
& a=d_{h k i}\left(h^{2}+k^{2}+i^{2}\right)^{1 / 2}
\end{aligned}
$$

The calculated values ( $d=2,50860 \AA$ and $\mathrm{a}=8,3181 \AA$ ) are extremely close to the standard values for $\mathrm{Fe}_{3} \mathrm{O}_{4}(\mathrm{~d}=2,5320 \AA$ and $\mathrm{a}=8,3960 \AA$ ) recorded in JCPDS file (JCPDS 19-0629). The final samples are reported to be magnetite $[25,26]$.

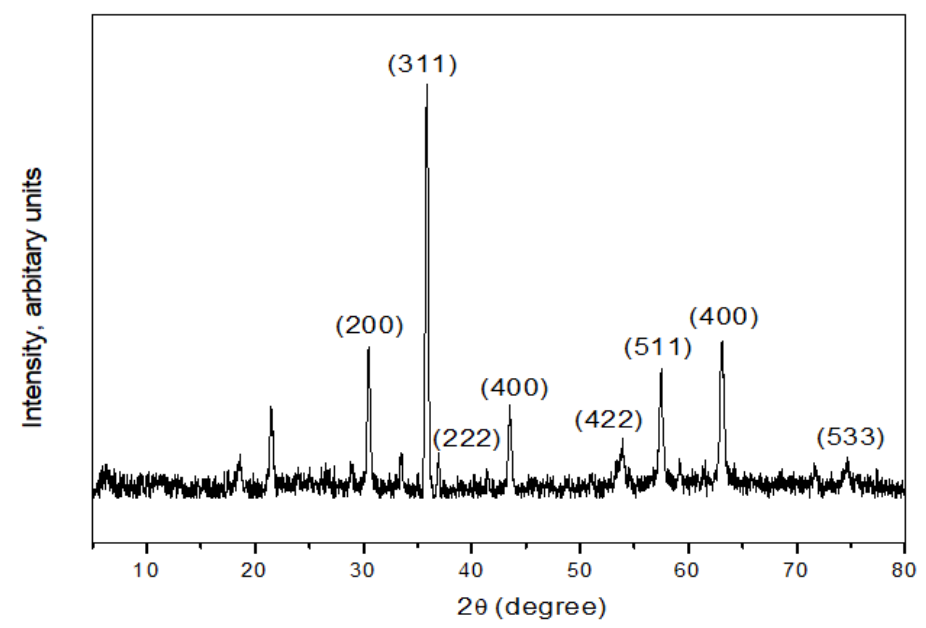

Figure 2. X-ray diffraction spectra of PMNs.

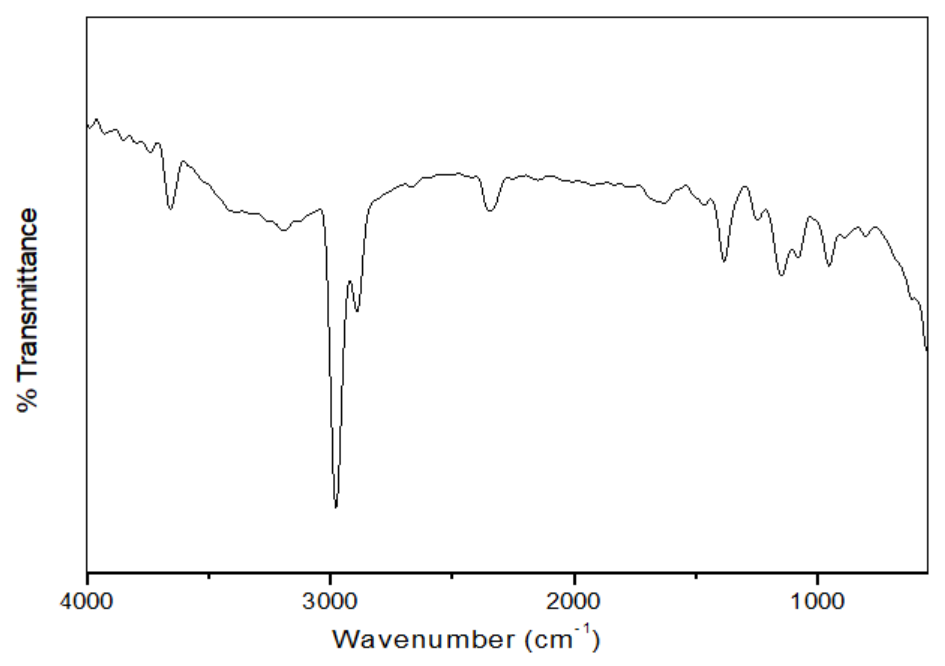

Figure 3. FTIR spectrum of PMNs. 


\subsubsection{Fourier-transform infrared (FTIR) analysis.}

FT-IR between 4000 and $400 \mathrm{~cm}^{-1}$ was used to examine the functional groups present in the material PMNs. The spectrum of PMNs with FT-IR is shown in Figure 3. The bands of absorption obtained at $2977 \mathrm{~cm}^{-1}$ correspond to the $\mathrm{O}-\mathrm{H}$ strain [27]. The peak at $614 \mathrm{~cm}^{-1}$ correspond to $\mathrm{Fe}-\mathrm{O}$ bond. It indicates the magnetic core's existence and is even more noticeable in the magnetite nanoparticles [28].

\subsubsection{Brunauer-Emmett-Teller (BET) surface area.}

The pores' surface area and volume are both very important factors to determine in a material porous because the pores' size and volume can significantly influence the properties of the materials and their application processing capability [29]. In general, this is achieved by measuring the Brunauer-Emmett-Teller (BET) surface area of the material. BET tests use a physisorption-based adsorption isotherm and the potential of a gas to be weakly bound to the material's exterior surface as it comes into contact. Physisorption is a reversible process, and so gas easily adsorbs and desorbs to the surface of the content. The volume of gas adsorbed at a series of different pressures, at a constant temperature, is calculated to give the adsorption isotherm. The temperature is usually held constant using liquid nitrogen; thus, the temperature is $\sim 77 \mathrm{~K}$. The sum of gas adsorbed is plotted against the relative pressures that give the graph called the adsorption isotherm. The curve form on the graph provides insight into the sort of pores that in the material Fig. 4. The adsorption isotherm of PMNs can be labeled as Type V, which indicates the existence of hysteresis loop, capillary condensation occurring in a mesoporous, limit uptake at high initial $\mathrm{P} / \mathrm{P}_{\mathrm{o}}$ loop is defined by mono-multilayer adsorption, while the 2nd loop represented the desorption [30].

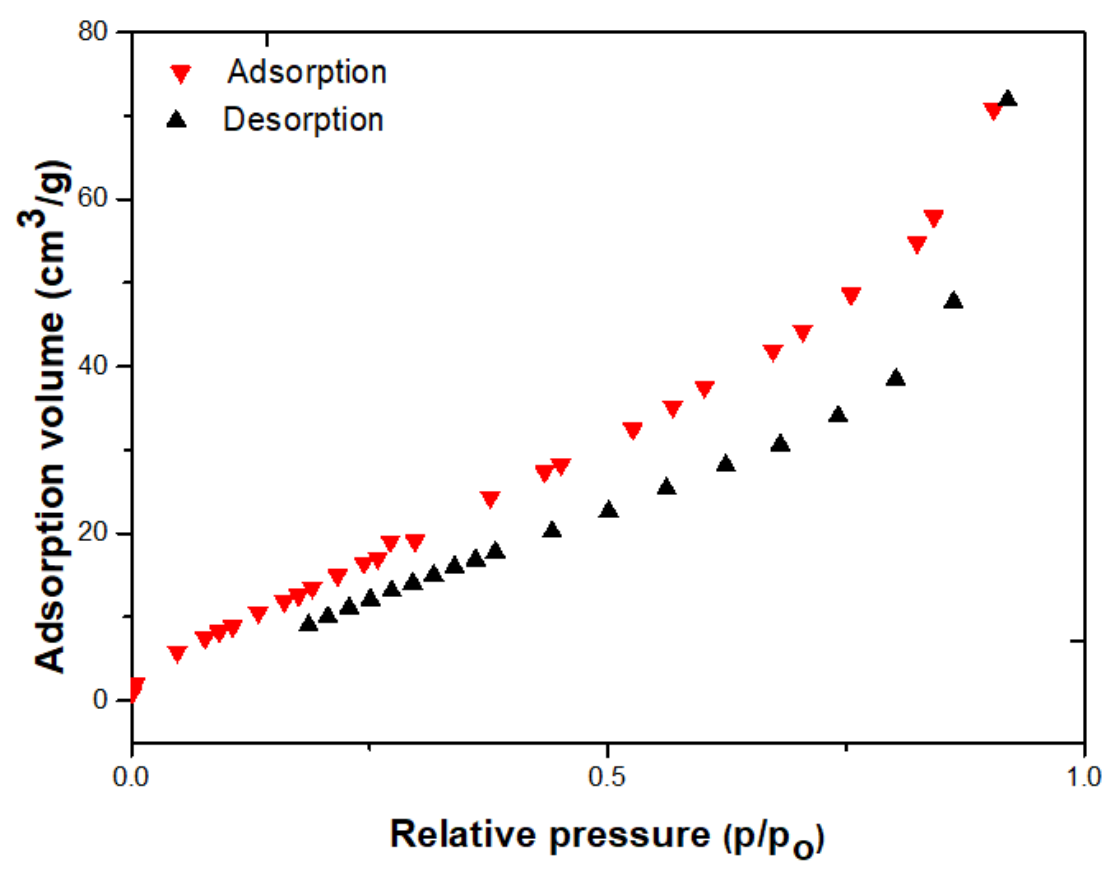

Figure 4. $\mathrm{N}_{2}$ sorption isotherm of PMNs.

The PMN's BET surface area was $143.65 \mathrm{~m}^{2} / \mathrm{g}$ with a value of $16.2 \AA$ for the $\mathrm{N}_{2}$ molecule's cross-sectional area. However, the total volume of pores at saturation pressure measured as the liquid volume is $0.161 \mathrm{~cm}^{3} / \mathrm{g}$. The average pore size of $2.24 \mathrm{~nm}$, which is helpful for application with adsorption. 


\subsubsection{SEM and TEM analysis.}

Scanning electron microscopy (SEM) and Transmission electron microscope (TEM) are well-thought-out as the key methods for clarifying surface morphology, the theory of physical properties, and PMNs. It is suitable for the determination of the adsorbent's porosity, morphology, and proper size. PMNs were analyzed via SEM and TEM. Figure 5 and Figure 6. The SEM and TEM study agreed that nanoparticles were PMNs because their average diameter was $\sim 25,84 \mathrm{~nm}$. PMNs have large pores in which the related hood of adsorption and dye trapping is high in these pores. TEM also shows clearly that PMN particles are of a spherical form [31].

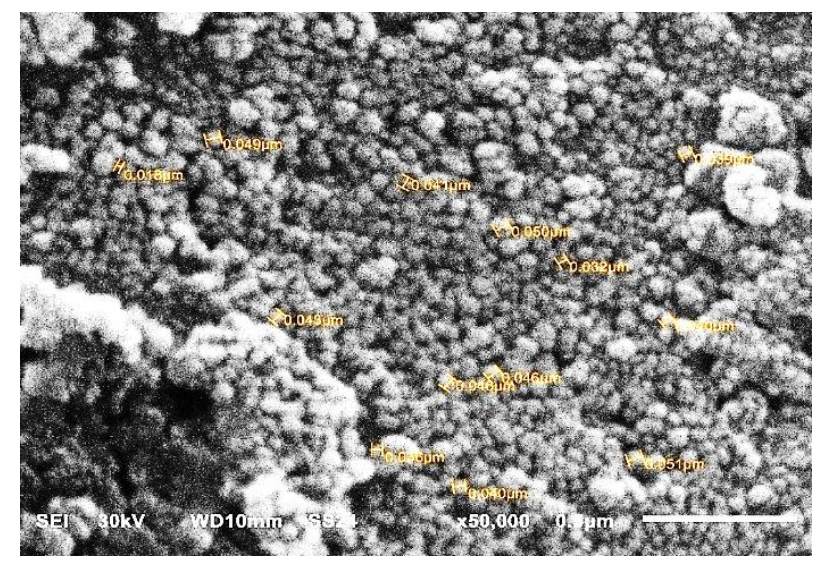

Figure 5. SEM image.

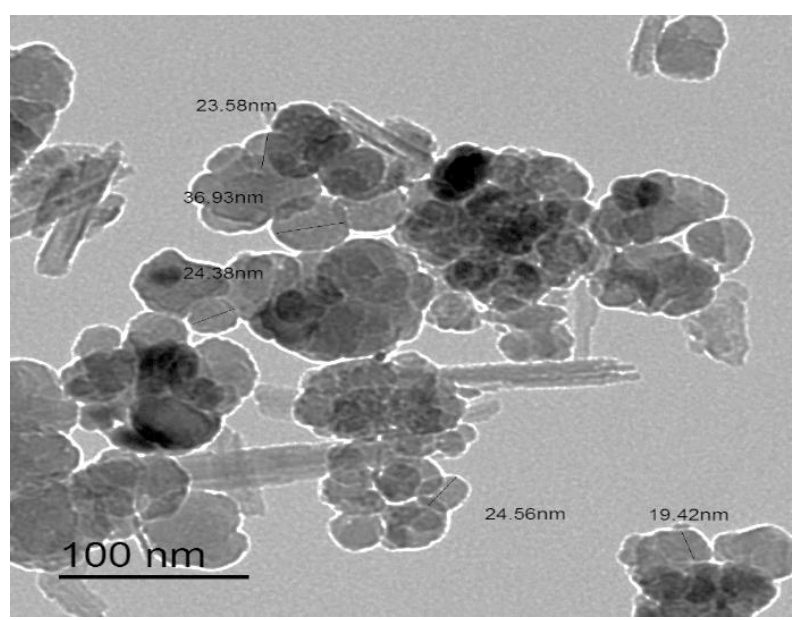

Figure 6. TEM image of PMNs.

\subsection{Batch experiments.}

\subsubsection{Determination of point of zero charge (pHPZC).}

One of the most important factors in the adsorption process was $\mathrm{pH}$, as it determined the form of adsorbent solution and the sorbent's surface load. The PZC measured the PMN's surface load, defined as the $\mathrm{pH}$ (pHpzc), at which the positive surface load is equal to the negative load [20]. PMNS pHPZC was found to be at 4.3.

Under this $\mathrm{pH}$, the PMNs obtain a positive charge due to the functional group's protonation, and there is a negative charge on the PMNs surface above this $\mathrm{pH}$. Adsorption of anionic colors is favored at $\mathrm{pH}<\mathrm{pHPzC}$, where the surface is negatively charged (Figure 7). 


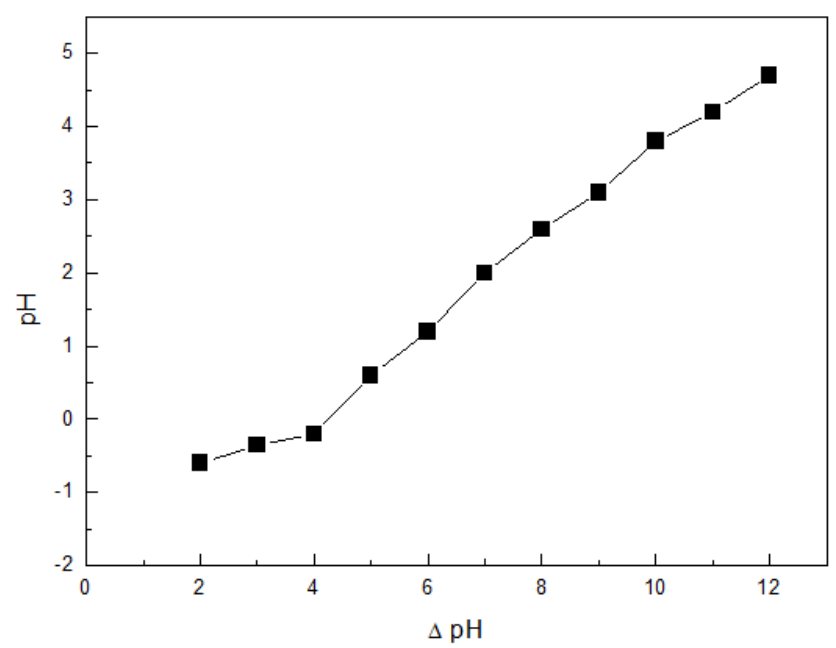

Figure 7. Relation between the initial $\mathrm{pH}$ and $\Delta \mathrm{pH}$ of PMNs.

\subsubsection{Effect of $\mathrm{pH}$.}

The solution $\mathrm{pH}$ is one of the most important factors affecting the adsorbent potential in removing dye. Variation of $\mathrm{pH}$ affects the acid-base composition of the solution and affects the surface load of PMNs; this is critical for the adsorption of ionic colors. The adsorption potential for the PMNs adsorption process increased with $\mathrm{pH}$ range from 2 to 4 (Figure 8).

The removal of the tested dyes AR57 and RR by PMNs nanoparticles at different $\mathrm{pH}$ values (2-12) was studied at Concentrations of $1.83 \times 10^{-4} \mathrm{molL}^{-1}$ of the adsorbent dose of $\mathrm{AR} 57,25^{\circ} \mathrm{C}$, and $0.02 \mathrm{~g}$ were examined, while the initial concentration of $\mathrm{RR}, 25^{\circ} \mathrm{C}$, and 0.02 $\mathrm{g}$ of PMN were $1.51 \times 10^{-4} \mathrm{molL}^{-1}$. The adsorption efficiency of AR57 and RR decreased slightly with a further increase of $\mathrm{pH}[32,33]$.

This AR57 and RR adsorption pattern can be explained by the PMN's Zero Charging Point (pHpzc), and the pHpzc has been specified at 4.3. These two anionic dyes, AR57 and RR, exist stably in the studied $\mathrm{Ph}$ range in their anionic form; thus, adsorption capacity increased slowly due to positive charged PMNs. The quantity of $\mathrm{OH}^{-}$in solution increases with $\mathrm{pH}$ rise, and $\mathrm{OH}^{-}$excess clashes with two selected dyes to attract PMNs and adsorb them on their disabled sites.
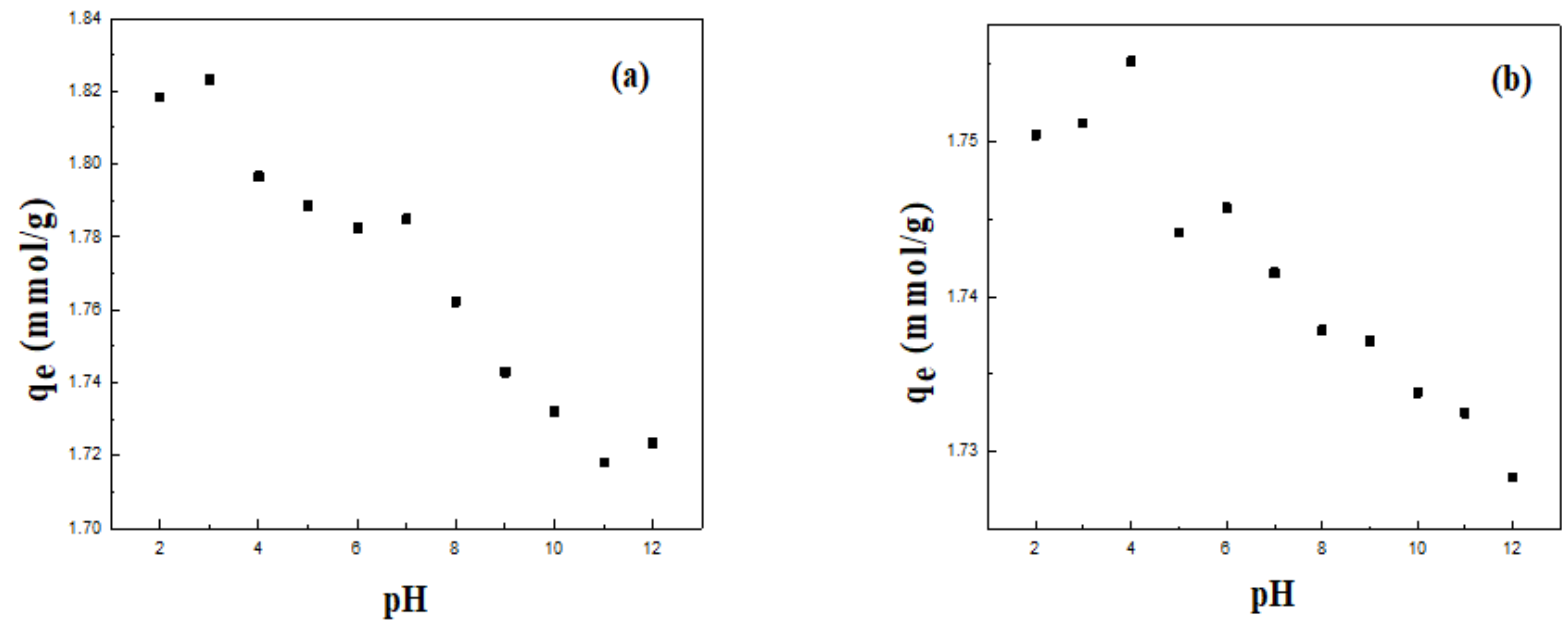

Figure 8. (a) $\mathrm{pH}$ effect on AR57 adsorption using the adsorbent (PMNs): $\left(\mathrm{T}: 25^{\circ} \mathrm{C} ; \mathrm{C}_{0}: 1.83 \times 10^{-4} \mathrm{molL}^{-1}\right)$; (b) $\mathrm{pH}$ effect on RR adsorption using the adsorbent (PMNs): (T: $\left.25^{\circ} \mathrm{C} ; 1.51 \times 10^{-4} \mathrm{molL}^{-1}\right)$.

Thus, under alkaline conditions, the adsorption of AR57 and RR on PMNs decreases; high ability adsorption occurs when there is heavy electrostatic cooperation between the $\mathrm{Fe}^{3+}$ 
Cation and $\mathrm{SO}^{3-}$ dye anions at a strongly acidic $\mathrm{pH}$ as the attraction between the PMNs is charged positively surface and the acid (anionic) dyes. When the system's $\mathrm{pH}$ increases, the number of negatively charged sites is increasing, and the number of positively charged sites is rising. Based on the above results, the slight suggested the presence of another force supporting the process, and reference could be made to the hydrogen bonding [34,35].

\subsubsection{Effect of adsorbent dosage.}

The adsorption of AR57 and RR in PMNs nanosphere was determined by adjusting the adsorbent range $\left((0.01\right.$ to 0.1$\left.) \mathrm{g} 25 \mathrm{~mL}^{-1}\right)$, adsorbent concentration $\left(1.83 \times 10^{-4} \mathrm{molL}^{-1}\right.$ at 25 ${ }^{\circ} \mathrm{C}$ ), and $\mathrm{pH}(3)$ for AR57. For RR, a concentration of $1.51 \times 10^{-4} \mathrm{molL}^{-1}$ at $25{ }^{\circ} \mathrm{C}$ and $\mathrm{pH} 4$ were used. The findings are from Figures 9a and 10a indicate the adsorption potential of AR57 and RR as a function of the adsorbent dose. The adsorption capacity for AR57 and RR grows from 3.55 to $0.434 \mathrm{mmol} / \mathrm{g}$ and from 3.5 to $0.37 \mathrm{mmol} / \mathrm{g}$, respectively, when the PMNs dosage rises from 0.01 to $0.1 \mathrm{~g} 25 \mathrm{~mL}$. Figures $9 \mathrm{~b}$ and $10 \mathrm{~b}$ show the effect of PMN-sorbent dosage on equilibrium concentration $\left(\mathrm{C} / \mathrm{C}_{0}\right)$ of AR57 and RR. As the dose increases, the AR57 and RR balance concentration is reduced. This is because of the increased surface adsorption of the PMNs. The results showed that the efficiency of removal increases to $95.15 \%\left(C / \mathrm{C}_{0}=0.048\right)$ at an adsorbent dosage of $0.1 \mathrm{~g}, 25 \mathrm{~mL}, \mathrm{C}_{0}: 1.83 \times 10^{-4} \mathrm{molL}^{-1}$ and $\mathrm{pH}=3$ for AR57, while for $\mathrm{RR}$, the removal efficiency rises to $98.3 \%\left(\mathrm{C} / \mathrm{C}_{0}=0.017\right)$ at an adsorbent dosage of $0.1 \mathrm{~g}, 25$ $\mathrm{mL}, \mathrm{C}_{0}: 1.51 \times 10^{-4} \mathrm{molL}^{-1}$ and $\mathrm{pH}=4$. The adsorbent surface is self-possessed by active sites possessing a variety of binding energies[36]. At low adsorbent concentration, all the sites are completely exposed. The adsorbent surface is saturated faster, indicating higher adsorption efficiency. An increase in adsorbent mass leads to a reduction in the adsorption potential for equilibrium per unit adsorbent weight $\left(\mathrm{q}_{\mathrm{e}}\right)$ since excess adsorbent is present in the solution for the restricted amount of AR57 and RR ions[37].

The result is that the $0.01 \mathrm{~g} 25 \mathrm{~mL}$ dosage achieves the full load capacity for the sorbent, and the $0.1 \mathrm{~g} 25 \mathrm{~mL}$ dosage achieves the full removal efficiency of $95.15 \%\left(\mathrm{C} / \mathrm{C}_{0}=0.048\right)$ for AR57 and $98.3 \%\left(C / \mathrm{C}_{0}=0.017\right)$ for $\mathrm{RR}$. Therefore, determining the optimal dose of adsorbents depends on the nature and purpose of the treatment processes. If the goal is the WHO's water quality norm, a greater quantity of PMNs is ideal $(0.1 \mathrm{~g} 25 \mathrm{~mL})$, and if the goal is the average sorbent load per unit mass, the dose of $(0.01 \mathrm{~g} 25 \mathrm{~mL})$ is more appropriate.
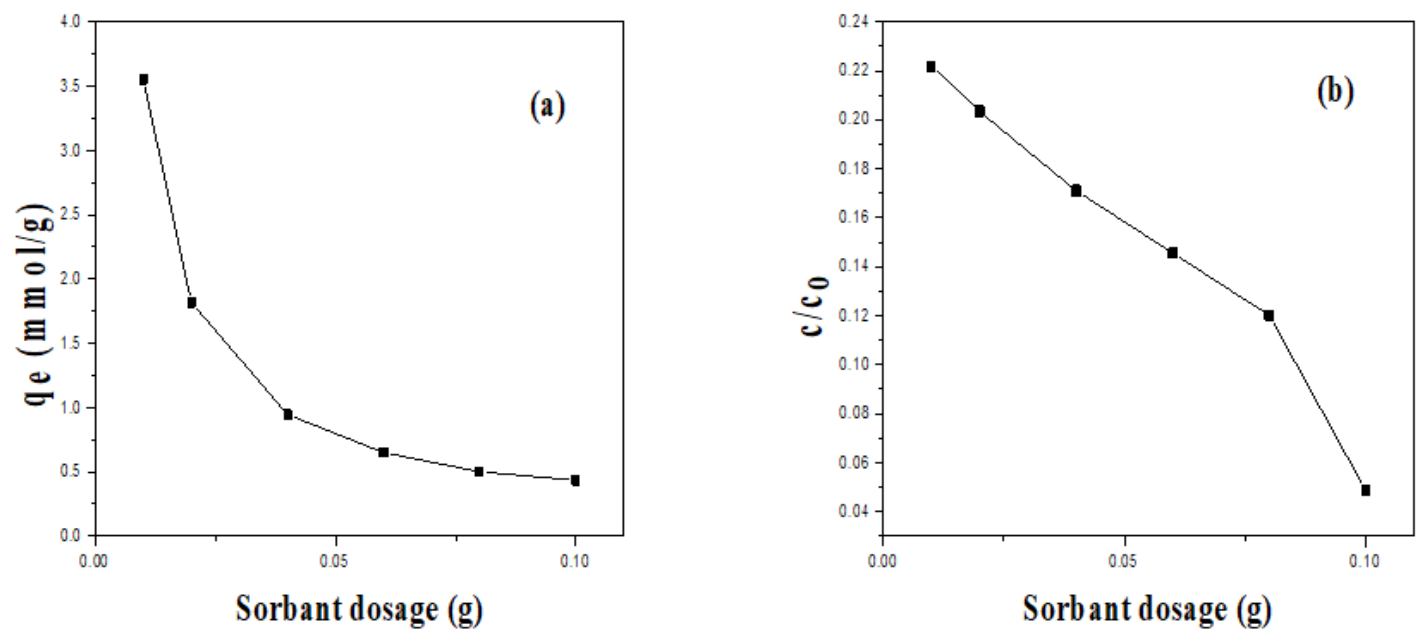

Figure 9. Effect of PMNs dosage on AR57 adsorption: (a) Sorption capacity $v s$. SD; (b) relative residual concentration $\left(\mathrm{C} / \mathrm{C}_{0}\right)$ vs. SD $\left(\mathrm{C}_{0}: 1.83 \times 10^{-4} \mathrm{molL}^{-1} ; \mathrm{T}: 25^{\circ} \mathrm{C} ; \mathrm{pH} 3\right)$. 

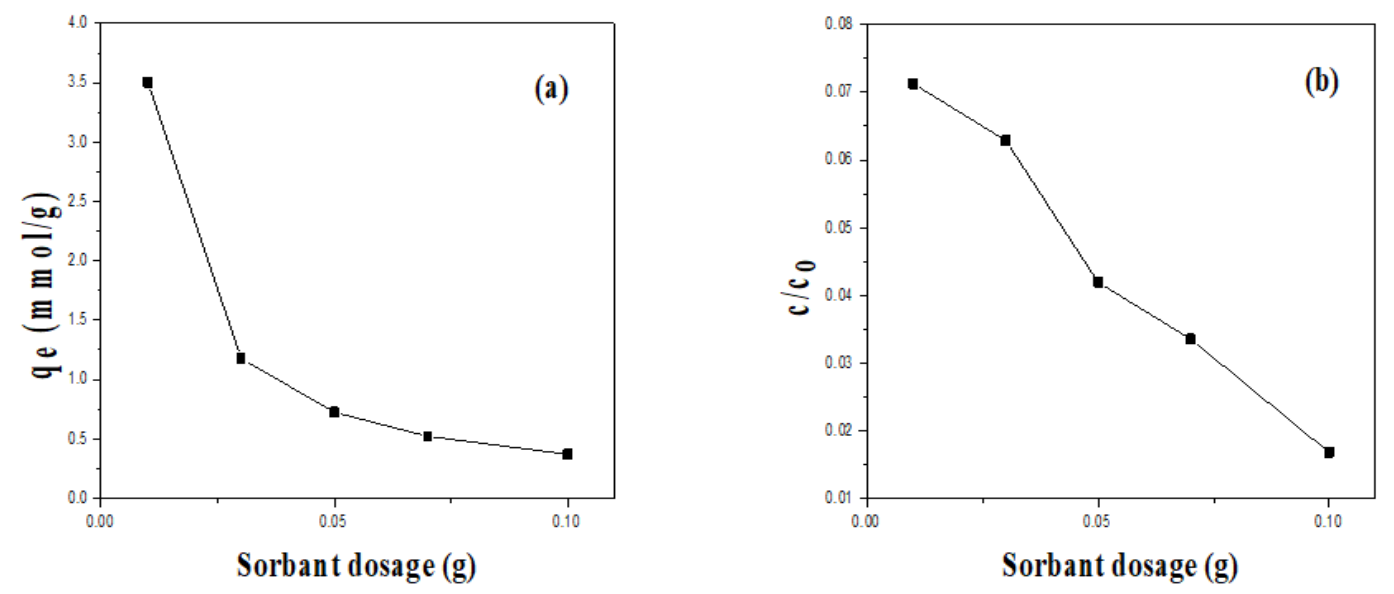

Figure 10. Effect of PMNs dosage on (a) RR adsorption sorption capacity $v s$. SD; (b) relative residual concentration $\left(\mathrm{C} \mathrm{C}_{0}\right)$ vs. SD $\left(\mathrm{C}_{0}: 1.51 \times 10^{-4} \mathrm{molL}^{-1} ; \mathrm{T}: 25^{\circ} \mathrm{C} ; \mathrm{pH} 4\right)$.

\subsubsection{Effect of contact time.}

Study the adsorption of tested dyes AR 57 and RR onto PMNs was examined with dye concentrations ranging from $8.85 \times 10^{-5}$ to $3.94 \times 10^{-4} \mathrm{molL}^{-1}$ and $9.32 \times 10^{-5}$ to $1.91 \times 10^{-4} \mathrm{molL}^{-1}$ for AR57 at pH 3 and $0.02 \mathrm{~g}$ adsorbent dosage and $\mathrm{RR} \mathrm{pH} 4$ and $0.02 \mathrm{~g}$ adsorbent dosage, respectively the removal increases with time and attains saturation in about 5-100 mins with $200 \mathrm{rpm}$ agitation speed. The findings showed that the dye's adsorption was rapid at the initial stage of the adsorption reaction $(60 \mathrm{~min})$ of the adsorbent/adsorbent interaction, and the quantity removal rate was almost negligible due to the rapid adsorption site exhaustion. At first, the rate of removal of the dye volume is higher since the adsorbent's greater surface area is available for adsorption of the dye [38]. However, all the sites were now colored as the reaction bears equilibrium, and thus the adsorption was slow [39].

\subsubsection{Effect initial concentration $\left(\mathrm{C}_{0}\right)$.}

The impact of the initial concentration of tested dyes AR 57 and RR onto PMNs was examined with dye concentrations ranging from $8.85 \times 10^{-5}$ to $3.94 \times 10^{-4} \mathrm{molL}^{-1}$ and $9.32 \times 10^{-5}$ to $1.91 \times 10^{-4} \mathrm{molL}^{-1}$ for AR57 at $\mathrm{pH} 3$ and $0.02 \mathrm{~g}$ adsorbent dosage and $\mathrm{RR} \mathrm{pH} 4$ and $0.02 \mathrm{~g}$ adsorbent dosage, respectively, with time and achieved a maximum value at $90 \mathrm{~min}$. The percentage removal decreased as the initial dye concentration of AR57 and RR increased. The percentage reduction in adsorption was due to the depletion of the PMNs active binding sites at higher AR57 and RR concentrations [40].

\subsubsection{Adsorption isotherms.}

Isotherm studies give significant visions by clarifying the adsorbate distribution between solid and solution phase during the adsorption equilibrium, and adsorption isotherms expose the behavior of adsorbate how to interact with adsorbent. Equilibrium revisions that give the adsorbent and adsorbate capacity are described by adsorption isotherms, which is usually the ratio between the quantity adsorbed and that remained in solution at equilibrium at fixed temperature. Numerous isotherm models have been used for considering the equilibrium adsorption of compounds from solutions such as Langmuir [41], Freundlich [42], DubininRadushkevich [43], and Temkin [44]. 
The Langmuir isotherm model accepts the uniform energies of adsorption onto the adsorbent surface. It is based on a statement of monolayer adsorption's existence onto a completely homogeneous surface with a fixed number of identical sites and negligible interaction between adsorbed molecules [45, 46]. The Freundlich model is an empirical equation based on adsorption of heterogeneous surface or surface supporting sites of varied affinities. It is assumed that the stronger binding sites are occupied first and that the binding strength decreases with the increasing degree of site occupation. Dubinin-Radushkevich isotherm is an empirical model initially for the adsorption of subcritical vapors onto micropore solids following a pore-filling mechanism. It is applied to distinguish the physical and chemical adsorption for removing a molecule from its location in the sorption space to the infinity. The Temkin isotherm assumes that the heat of adsorption of all molecules in the phase decreases linearly when the layer is covered and that the adsorption has a maximum energy distribution of uniform bond.

\subsubsection{Langmuir isotherms.}

Langmuir adsorption, originally developed to describe liquid-solid adsorption processes, is often used to calculate and contrast the adsorption potential of various adsorbents [41]. Langmuir isotherm accounts for the surface distribution by matching relative velocities of adsorption and desorption (dynamic equilibrium). Adsorption is proportional to the fraction of the adsorbent's exposed surface, while desorption is proportional to the fraction of the protected adsorbent surface [47]. In the linear form, the Langmuir equation can be written as follows $\mathrm{Eq}(7)$ :

$$
\frac{\mathrm{C}_{\mathrm{e}}}{\mathrm{q}_{\mathrm{e}}}=\frac{1}{\mathrm{q}_{\mathrm{m}} \mathrm{K}_{\mathrm{L}}}+\frac{\mathrm{C}_{\mathrm{e}}}{\mathrm{q}_{\mathrm{m}}}
$$

where $\mathrm{C}_{\mathrm{e}}$ is equilibrium adsorbate concentration $\left(\mathrm{mmolg}^{-1}\right)$. $\mathrm{K}_{\mathrm{L}}$ is Langmuir constant related to adsorption capability $\left(\mathrm{mmolg}^{-1}\right)$, which can be correlated with the variation in the appropriate area and adsorbent porosity, which means that the wide surface area and pores volume results in a higher adsorption efficiency.

The constants $\mathrm{q}_{\mathrm{m}}$ and $\mathrm{K}_{\mathrm{L}}$ are measured using the plot $\mathrm{C}_{\mathrm{e}} / \mathrm{q}_{\mathrm{e}}$ vs. $\mathrm{C}_{\mathrm{e}}$ with slope $1 / \mathrm{q}_{\mathrm{m}}$ and intercept $1 /\left(\mathrm{q}_{\mathrm{m}} \mathrm{K}_{\mathrm{L}}\right)$. The critical characteristics of the Langmuir isotherm can be indicated by a dimensionless constant called the separation factor $\mathrm{R}_{\mathrm{L}} \mathrm{Eq}(8)$ :

$$
\mathrm{R}_{\mathrm{L}}=\frac{1}{1+\mathrm{c}_{0} \mathrm{~K}_{\mathrm{L}}}
$$

where $\mathrm{K}_{\mathrm{L}}$ is Langmuir constant $\left(\mathrm{mmolg}^{-1}\right)$, and $\mathrm{C}_{0}$ is the initial concentration of adsorbate $\left(\mathrm{mmolg}^{-1}\right)$. $\mathrm{R}_{\mathrm{L}}$ values indicate the adsorption to be unfavorable when $R L>1$, linear when $R_{L}=$ 1, favorable when $0<R_{L}<1$, and irreversible when $R_{L}=0$.

\subsubsection{Freundlich Isotherms:}

Freundlich isotherm is true for adsorption processes that occur on a heterogeneous surface [42]. This isotherm explains the surface heterogeneity and the exponential distribution of the active sites and their energies [48]. The Freundlich isotherm linear form is as follows [49] Eq (9):

$$
\ln \mathrm{q}_{\mathrm{e}}=\ln \mathrm{K}_{\mathrm{F}}+\frac{1}{\mathrm{n}} \ln \mathrm{C}_{\mathrm{e}}
$$


where $\mathrm{K}_{\mathrm{F}}$ is adsorption capacity $\left(\mathrm{mmoLg}^{-1}\right)\left(\mathrm{Lmmol}^{-1}\right)^{1 / n}$ and $1 / n$ is adsorption intensity. The relative energy distribution and the heterogeneity of the adsorbed sites are also indicated. $\mathrm{K}_{\mathrm{F}}$ and $\mathrm{n}$ can be calculated from a linear plot of $\ln \mathrm{q}_{\mathrm{e}} \mathrm{vs}$. $\ln \mathrm{C}_{\mathrm{e}}$

\subsubsection{Dubinin-Radushkevich Isotherms:}

Dubinin-Radushkevich isotherm model is an empirical adsorption model widely used to describe the adsorption processes with Gaussian energy distribution on heterogeneous surfaces. This isotherm is only ideal for intermediate adsorbent concentrations because it demonstrates an asymptotic activity, which is impractical.

The model is a semiempirical equation where adsorption is followed by a pore filling process [43]. This presumes a multilayer character involving Vander Waal's forces, applicable to physical adsorption processes, and is a fundamental equation that qualitatively defines the adsorption of AR57 and RR on PMNs [50] Eq (10):

$$
\ln \mathrm{q}_{\mathrm{e}}=\ln \mathrm{Q}_{\mathrm{DR}}-\mathrm{K}_{\mathrm{DR}} \varepsilon^{2}
$$

where the Polanyi potential is $\varepsilon\left(\mathrm{J}^{2} \mathrm{~mol}^{-2}\right)$. The gas constant is $\mathrm{R}\left(8.314 \mathrm{Jmol}^{-1} \mathrm{~K}^{-1}\right)$.

The $\ln \mathrm{q}_{\mathrm{e}}$ vs. $\varepsilon^{2}$ plot slope provides $\mathrm{K}_{\mathrm{DR}}\left(\mathrm{mol}^{2} / \mathrm{kJ}^{2}\right)$ and $\mathrm{Q}_{\mathrm{DR}}(\mathrm{mmol} / \mathrm{g})$ adsorption efficiency for the intercept yields [4].

\subsubsection{Temkin Isotherms.}

Temkin isotherm model considers the impact of indirect adsorbent/adsorbent interactions on the adsorption process; adsorption processes are also presumed; adsorption heat $\left(\Delta H_{\text {ads }}\right)$ of all layer molecules are also assumed to decrease linearly as a result of increasing surface coverage[44]. The Temkin isotherm is valid only for medium concentrations of ions. The linear form of the isotherm Temkin model is given by the following Eq (11):

$$
\mathrm{q}_{\mathrm{e}}=\beta_{\mathrm{T}} \ln \mathrm{K}_{\mathrm{T}}+\beta_{\mathrm{T}} \ln \mathrm{C}_{\mathrm{e}}
$$

The $\beta$ and $\mathrm{K}_{\text {т }}$ parameters are the Temkin constants, which can be calculated by the $\mathrm{q}_{\mathrm{e}}$ $v s$. ln ce plot. The parameter for linear and nonlinear forms of Langmuir, Freundlich, Dubinin-Radushkevich, and Temkin isotherm models are shown in Table 2.

\begin{tabular}{|c|c|c|c|}
\hline \multirow{2}{*}{ Models } & \multirow{2}{*}{ Parameter } & \multicolumn{2}{|c|}{ Dyes } \\
\hline & & AR57 & $\mathbf{R R}$ \\
\hline \multirow{5}{*}{ Langmuir } & $\mathrm{q}_{\mathrm{m} \exp }\left(\mathrm{mmolg}^{-1}\right)$ & 1.6 & 1.438 \\
\hline & $\mathrm{q}_{\mathrm{m}}\left(\mathrm{mmolg}^{-1}\right)$ & 1.62 & 1.437 \\
\hline & $\mathrm{K}_{\mathrm{L}}\left(\mathrm{Lmmol}^{-1}\right)$ & $2.18 \mathrm{E}+04$ & $1.11 \mathrm{E}+06$ \\
\hline & $\mathrm{R}_{\mathrm{L}}$ & 0.04 & 0.05 \\
\hline & $\mathrm{R}^{2}$ & 0.999 & 0.9999 \\
\hline \multirow{3}{*}{ Freundlich } & $\mathrm{n}$ & 9.07 & 16.24 \\
\hline & $\mathrm{K}_{\mathrm{F}}\left(\mathrm{mmoLg}^{-1}\right)\left(\mathrm{Lmmol}^{-1}\right)^{1 / \mathrm{n}}$ & 1.178 & 2.42 \\
\hline & $\mathrm{R}^{2}$ & 0.7985 & 0.52 \\
\hline \multirow{4}{*}{ Dubinin-Radushkevich } & QDR & 0.787 & 0.593 \\
\hline & $\mathrm{K}_{\mathrm{DR}}\left(\mathrm{J}^{2} \mathrm{~mol}^{-2}\right)$ & $-1.22 \mathrm{E}-09$ & $-5.11 \mathrm{E}-10$ \\
\hline & $\mathrm{Ea}\left(\mathrm{kJmol}^{-1}\right)$ & 20.24 & 31.3 \\
\hline & $\mathrm{R}^{2}$ & 0.848 & 0.563 \\
\hline \multirow{3}{*}{ Temkin } & $\mathrm{b}_{\mathrm{T}}\left(\mathrm{Lmol}^{-1}\right)$ & 16799.38 & 33957.95 \\
\hline & $\mathrm{A}_{\mathrm{T}}\left(\mathrm{kJmol}^{-1}\right)$ & 17.24 & 28.16 \\
\hline & $\mathrm{R}^{2}$ & 0.8388 & 0.5226 \\
\hline
\end{tabular}

Table 2. Isotherms and their linear forms for the adsorption of AR57 and RR onto PMNs. 
Finally, the Langmuir isotherm model is the best match, so the most appropriate model is considered to define the isotherm for the adsorption of both AR57 and RR colors with PMNs sorbent figure 11 to 14 for AR57 and RR. The Langmuir model presented AR57 and RR with a strong correlation coefficient $\mathrm{R}^{2}=0.9999$.
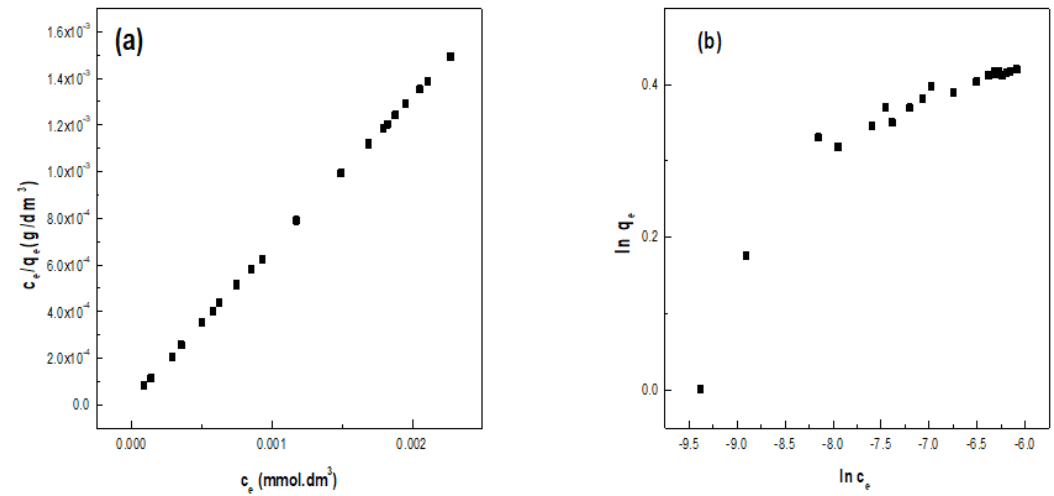

Figure 11. Linearized plots for sorption isotherms for AR57: (a) Langmuir equation; (b) Freundlich equation.
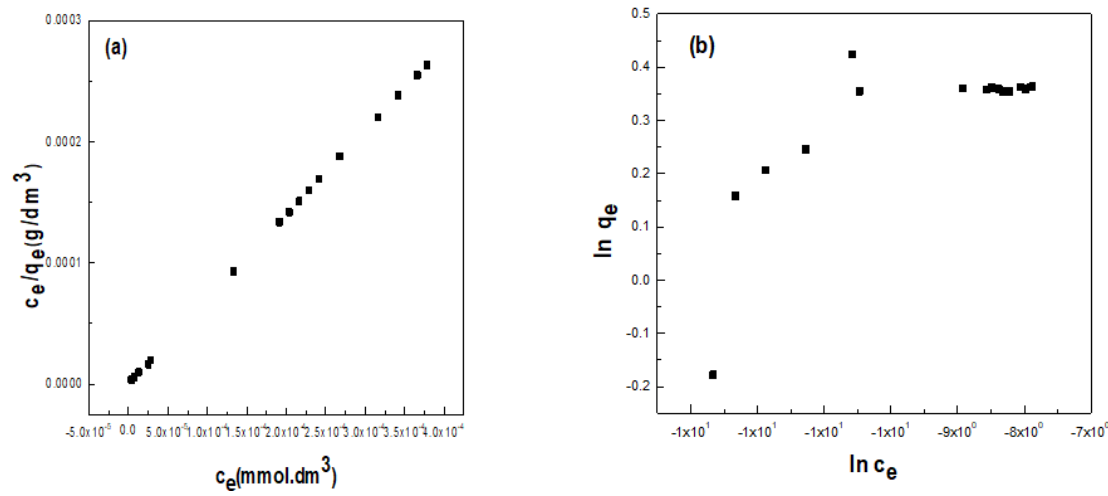

Figure 12. Linearized plots for sorption isotherms for RR: (a) Langmuir equation; (b) Freundlich equation.
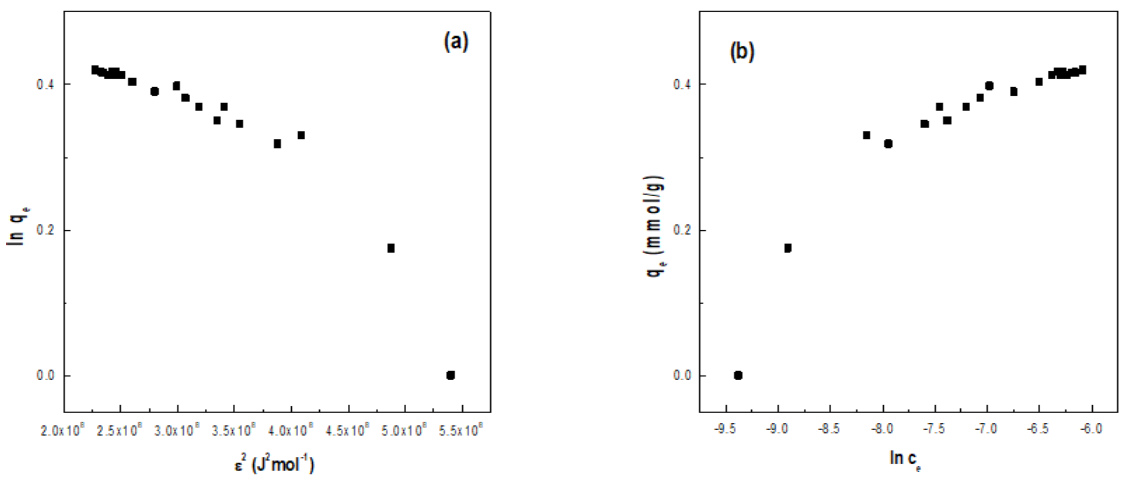

Figure 13. Linearized plots for sorption isotherms for AR57: (a) Dubbin-Radushkevich equation; (b) Temkin model.
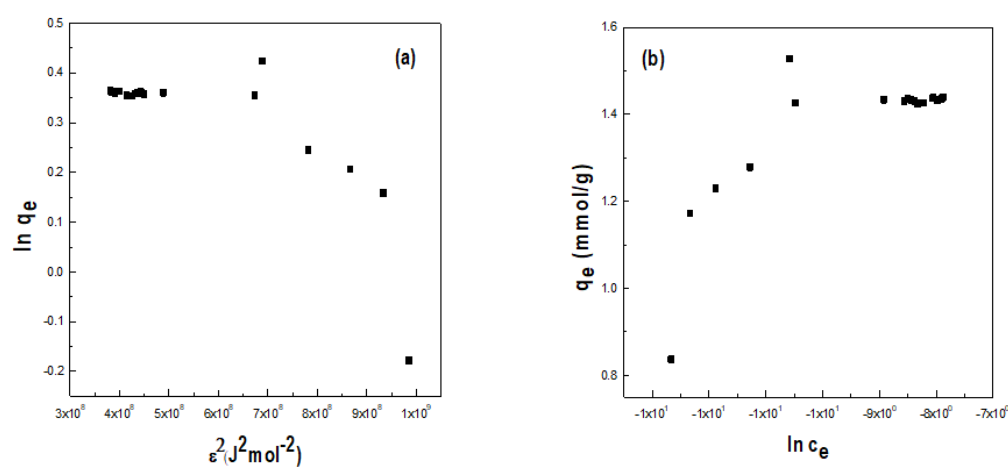

Figure 14. Linearized plots for sorption isotherms for RR: (a) Dubbin-Radushkevich equation; (b) Temkin model. 
Moreover, Table 2 shows that the $\mathrm{q}_{\mathrm{m}}$ calculated from the Langmuir isotherm was identical to the experimental $\mathrm{q}_{\max }$. Also, for AR57 and RR, the $\mathrm{R}_{\mathrm{L}}$ value was approximately 0.04 and 0.05 , which indicate a favorable adsorption behavior.

For AR57 and RR, respectively, the Dubinin-Radushkevich isotherm results are shown in Table 2 and Figs 13 and 14. Chemisorption processes are claimed to be the mean energy value of the adsorption isotherm. Indeed, it is generally admitted that $8 \mathrm{~kJ}^{\mathrm{mol}}{ }^{-1}$ is the limit

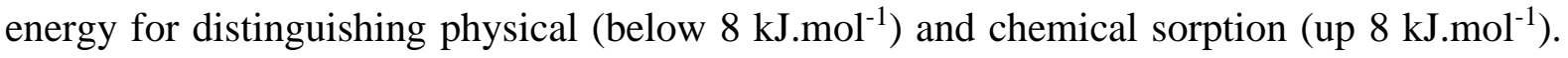
Even given the porous sorbent effect and the energy involved in the sorption processes, this isotherm was traditional. This finding suggests that the binding of dye ions on the sorbent surface may occur as a monolayer. The absorption occurs on a homogenous surface by monolayer sorption. That should be based on experimental observation for validation. Consoling the homogeneous surface hypothesis (or homogeneous sorption energies) is the presence of the same type of functional groups.

A summary of the correlation coefficient values derived from the isotherm models Langmuir, Freundlich, Dubinin-Radushkevich and Temkin Table 2, shows that the correlation coefficients for Langmuir are higher than those for the isotherm models Freundlich, DubininRadushkevich and Temkin. This finding suggests that the binding of dye ions on the sorbent surface may occur as a monolayer. The absorption occurs on a homogenous surface by monolayer sorption.

That should be based on experimental observation for validation. The presence of the same type of functional groups is consoling the earth's hypothesis (or homogeneous energies). The pattern classification as follows: Langmuir > DubinRadushkevich > Temkin > Freundlich, both for AR57 and RR.

\subsubsection{Adsorption kinetics and mechanism studies.}

The adsorption kinetics analysis defines the dyes' uptake rate, and this rate precisely regulates the adsorbate uptake residence time at the solid solution's interface. In the beginning, the degree of elimination of measured dye by adsorption was high. It then slowed down gradually until reaching an equilibrium above which the rate of removal increased significantly. The optimum adsorption was calculated at 100 minutes and is thus known as the equilibrium time.

\subsubsection{The pseudo-first-order.}

According to the kinetic model equations below the pseudo-first-order kinetic models were used to match the experimental results and obey the adsorb kinetics of tested dyes on PMNs.

Lagergren's pseudo-first-order rate formula [51] is given as Eq. 12:

$$
\log \left(q_{e}-q_{t}\right)=\log q_{e}-\left(\frac{K_{1}}{2.303}\right) t
$$

The $\ln \left(\mathrm{q}_{\mathrm{e}}-\mathrm{q}_{\mathrm{t}}\right)$ vs. $\mathrm{t}$ plot gives a straight line with the $-K_{l}$ slope and intercept $\ln \mathrm{q}_{\mathrm{e}}$

\subsubsection{The pseudo-second-order.}

The experimental data associated with a kinetic model of the pseudo-second-order. The kinetic model of the pseudo-second-order [52] is expressed as Eq. 13:

$$
\frac{t}{q_{t}}=\frac{1}{K_{2} q_{e}^{2}}+\frac{\mathrm{t}}{\mathrm{q}_{\mathrm{e}}}
$$


Values of $K_{2}$ and qe for various initial dye concentrations were determined from the slope and linear plot intercept of $\mathrm{t} / \mathrm{q}_{\mathrm{t}} v s$. $\mathrm{t}$.

Comparison of kinetic models, the pseudo-second-order kinetic model $\mathrm{R}^{2}$ values (0.9999) are much higher than those of the pseudo-first-order kinetic model (0.91472) for AR57, while the pseudo-second-order kinetic model $\mathrm{R}^{2}$ values (0.9999) for RR are much higher than those for the pseudo-first-order kinetic model (0.82202) Table 3, and the kinetic pseudosecond-order configuration is the perfect match for both the AR57 and RR colorants. The pseudo-second-order kinetic model qe (calc.) value is in true understanding with the experimental findings. The rate-limiting step in these adsorption processes may be chemisorption with strong forces through the sharing or exchange of electrons between sorbent and sorbate Figures 15 and 16.
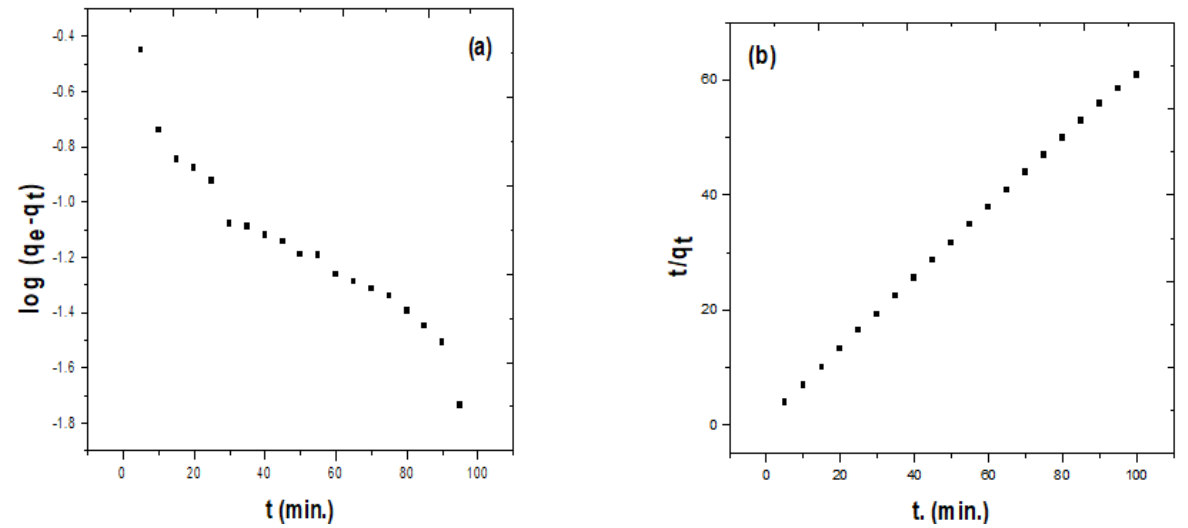

Figure 15. Modeling of uptake kinetics for AR57 with: (a) pseudo-first-order rate expression; (b) pseudosecond-order rate expression.
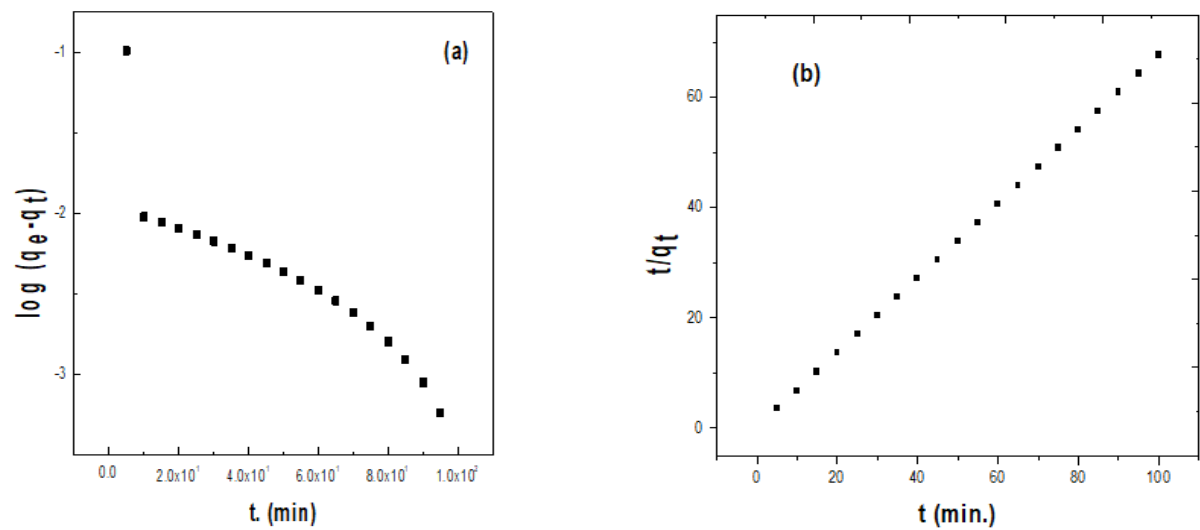

Figure 16. Modeling of uptake kinetics for RR with: (a) pseudo-first-order rate expression, (b) pseudo-secondorder rate expression.

\subsubsection{Webber (intraparticle diffusion).}

Weber postulated an empirical relationship with four parameters for a wide range of adsorption systems, which gave an excellent interpretation of the data pattern [53] Eq. 14:

$$
q_{t}=K_{i} t^{1 / 2}+X
$$

The Kdif and $\mathrm{C}$ parameters were calculated from the qt $v s . \mathrm{t}_{1 / 2}$ linear plot.

Webber's curve (intraparticle diffusion) provides multilinearity; it does not traverse the source. For AR57 and RR, respectively, the kinetic model of intraparticle diffusion (R2 = 0.23375 and 0.20884 ) was calculated from the slope of the corresponding second linear region (Figures 17 and 18). 
Only the initial stages of adsorption (initial sharp rise) are essential for the external resistance to mass transfer surrounding the particles. The second linear portion is the normal adsorption processes, with the regulation on intraparticle diffusion. Suppose the plots do not pass through the origin. In that case, this means that the pore diffusion is not the only ratelimiting step. However, other kinetic models can also regulate the adsorption rate, all of which can function simultaneously.

\subsubsection{Elovich.}

The equations which describe this model are based on a kinetic principle, which implies that adsorption sites increase exponentially with adsorption; this implies multilayer adsorption [54] Eq. 15:

$$
q_{t}=\frac{1}{\beta} \ln (\alpha \beta)+\frac{1}{\beta} \ln t
$$

The constants $\alpha$ and $\beta$ were obtained from a line plot qt vs. $\ln t$ on the slope and intercept, respectively.

The Elovich equation indicated that the adsorbent's active sites are heterogeneous and give different chemisorption activation energies. As the dye concentration increased, the constant $\alpha$ (attached to the rate of chemisorption) increased, and the constant $\beta$ (attached to the surface coverage) decreased (Figures 17 and 18), which is due to the decrease in the available adsorption surface for the adsorbates. Therefore, by increasing the concentration within the range studied, the chemisorption rate can be increased [55]. Table 3 shows the importance of all data concerning kinetic parameters.
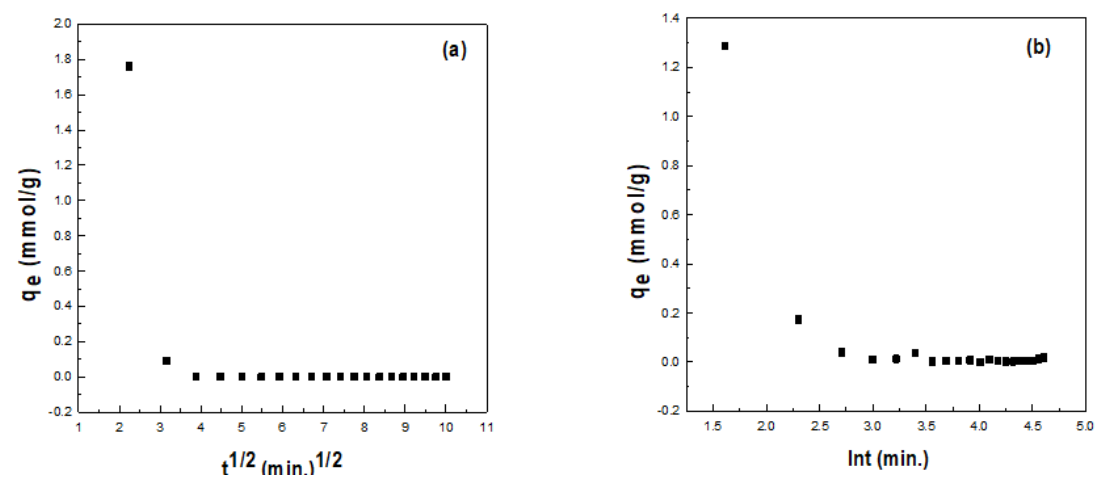

Figure 17. Modeling of uptake kinetics for AR57 with (a) simplified model of resistance to intraparticle diffusion (Morris and Weber equation); (b) Elovich equation.
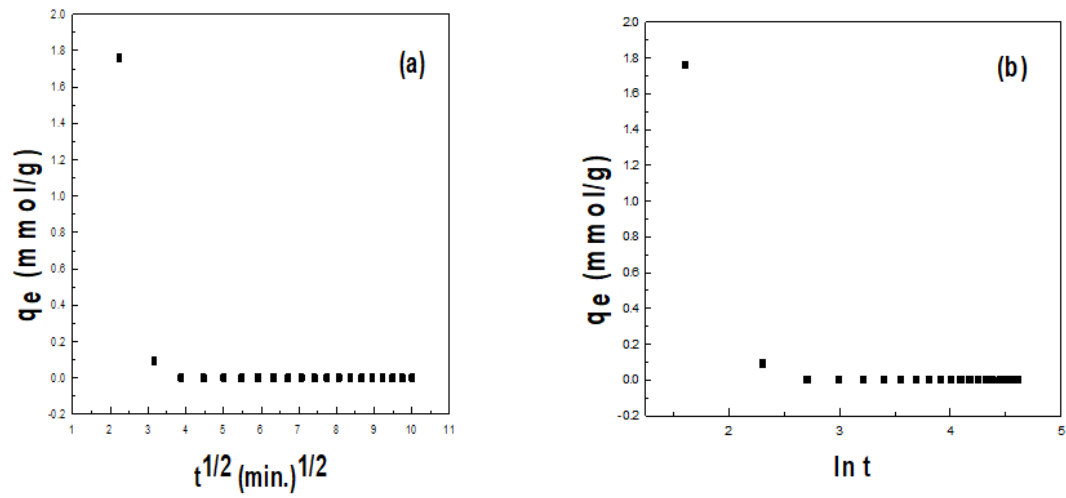

Figure 18. Modeling of uptake kinetics for RR with (a) simplified model of resistance to intraparticle diffusion (Morris and Weber equation); (b) Elovich equation.

Electrostatic interactions between the surface of the PMNs and negative ions AR57 and RR negative ions explain the adsorption mechanism as they considered anionic dyes containing 
one group of sulphonic acids $\left(-\mathrm{SO}_{3} \mathrm{Na}\right)$ in AR57 whereas $\left(-\mathrm{SO}_{3} \mathrm{H}\right)$ in $\mathrm{RR}$. In an aqueous solution, the dye separates hydrogen ions $\left(\mathrm{Fe}^{3+}\right)$. Sulfonate anions $\left(-\mathrm{SO}^{3-}\right)$ for RR and AR57 as AR57 dissociates from sodium ions $\left(\mathrm{Na}^{+}\right)$and sulfonate anions $\left(-\mathrm{SO}_{3}{ }^{-}\right)$while $\mathrm{RR}$ dissociates from hydrogen ions $\left(\mathrm{H}^{+}\right)$and sulfonate anions $\left(-\mathrm{SO}_{3}{ }^{-}\right)$.

However, at acidic $\mathrm{pH}$, the sulfonic groups may be protonated to the neutral form ($\mathrm{SO}_{3} \mathrm{H}$ ) due to their pKa values below zero, showing negative load even at higher acidic solutions. The mechanism analysis shows that the presence of $\mathrm{Fe}^{3+}$ on PMNs surface exposed to nanoparticles in a decisive role in high adsorption for AR57 and RR and the ionic bond between $\mathrm{Fe}^{3+}$ and $\left(-\mathrm{SO}_{3}{ }^{-}\right)$.

Therefore, at an acidic medium, the number of negatively charged sites on PMNs decreases, and the number of positively charged sites increases, enabling the adsorption of negatively charged dye ions due to the electrostatic force of attraction. Therefore, AR57 and RR's adsorption power to the PMN surface is favorable at lower pH (Eq. 16).

$$
\mathrm{ASO}_{2} \stackrel{\mathrm{H}^{+} \rightleftharpoons}{\rightleftharpoons} \mathrm{OSO}_{2}^{-}+\mathrm{Na}^{+}
$$

Table 3. Kinetic parameters and their correlation coefficients for the adsorption of AR57 and RR onto PMNs.

\begin{tabular}{c|c|c|c}
\multirow{2}{*}{ Models } & \multirow{2}{*}{ Parameter } & \multicolumn{2}{|c}{ Dyes } \\
\cline { 2 - 3 } & & AR57 & RR \\
\hline \multirow{3}{*}{ Pseudo-First-order kinetic } & $K_{l}\left(\mathrm{~min}^{-1}\right)$ & 0.0102 & -0.0157 \\
\cline { 2 - 4 } & $\mathrm{qe}_{\mathrm{e}}\left(\mathrm{mmolg}^{-1}\right)$ & -0.19 & 0.20475 \\
\cline { 2 - 4 } & $\mathrm{R}^{2}$ & 0.91472 & 0.82202 \\
\hline \multirow{3}{*}{ Pseudo-second-order kinetic } & $K_{2}\left(\mathrm{~g} \mathrm{mg}^{-1} \mathrm{~min}^{-1}\right)$ & 0.328 & 3.47 \\
\cline { 2 - 4 } & $\mathrm{q}_{\mathrm{e}}\left(\mathrm{mmolg}^{-1}\right)$ & 1.64 & 1.47 \\
\cline { 2 - 4 } & $\mathrm{R}^{2}$ & 0.9997 & 0.9999 \\
\hline \multirow{2}{*}{ Intraparticle diffusion } & $\mathrm{K}_{\mathrm{i}}\left(\mathrm{mgg}^{-1} \mathrm{~min}^{1 / 2}\right)$ & -0.0676 & -0.068 \\
\cline { 2 - 4 } & $\mathrm{X}\left(\mathrm{mgg}^{-1}\right)$ & 0.548 & 0.542 \\
\cline { 2 - 4 } & $\mathrm{R}^{2}$ & -4.2 & 0.215 \\
\hline \multirow{2}{*}{ Elovich } & $\beta\left(\mathrm{g}^{-1} \mathrm{mg}\right)$ & 2.63 & -4.13 \\
\cline { 2 - 4 } & $\alpha\left(\mathrm{mgg}^{-1} \cdot \mathrm{min}^{-1}\right)$ & 0.428 & 0.379 \\
\cline { 2 - 4 } & $\mathrm{R}^{2}$ & 1.64 & 1.47
\end{tabular}

\subsubsection{Thermodynamic parameters.}

The effect of temperature on adsorption needs to be studied in light of practical application. The adsorption experiments were carried out at 5 different temperature degrees: $298,303,308,313$, and $318 \mathrm{~K}$. The capacity for adsorption increases marginally from 1.415 to $1.57 \mathrm{mmol} . \mathrm{g}^{-1}$ for AR57 and from 1.538 to $1.609 \mathrm{mmol.g}{ }^{-1}$ for RR with an increase in temperature from 298 to $318 \mathrm{~K}$. This behavior shows that AR57 and RR adsorption processes to PMNs are endothermic. This finding may be due to increased mobility of dye molecules and the diffusion rate of adsorbent molecules across the surface of higher temperature PMNs, resulting in increased adsorption efficiency. This conduct indicates that the processes of adsorption of AR57 and RR to PMNs are endothermic. This finding can be due to increased mobility of dye molecules and the diffusion rate of adsorbent molecules across the surface of PMNs with higher temperatures, resulting in increased adsorption efficiency.

The dye adsorption was confirmed by the pseudo-second-order rate constant [56]. The following Arrhenius type relationship (Eq. 17) states as a temperature relation:

$$
\ln \mathrm{k}_{2}=\ln \mathrm{A}-\mathrm{E}_{\mathrm{a}} / \mathrm{RT}
$$


$\mathrm{K}_{\mathrm{c}}$ is the adsorption equilibrium constant calculated by Eq. 18 and applied with the Van't Hoff equation Eq. 19 and conventional thermodynamic equation Eq. 20 and 21 for measuring the thermodynamic constants of the sorbents

$$
\mathrm{K}_{\mathrm{c}}=\frac{q_{e}}{C_{e}}
$$

where $\mathrm{q}_{\mathrm{e}}$ and $\mathrm{C}_{\mathrm{e}}$ are equilibrium concentrations of AR57 and RR on the adsorbent and in the solution, respectively.

$$
\begin{aligned}
\Delta \mathrm{G}^{\mathrm{o}} & =-\mathrm{RT} \ln \mathrm{K}_{\mathrm{c}} \\
\Delta \mathrm{G}^{\mathrm{o}} & =\Delta \mathrm{H}^{\mathrm{o}}-\mathrm{T} \Delta \mathrm{S}^{\mathrm{o}}
\end{aligned}
$$

Therefore the Van't Hoff equation becomes:

$$
\ln K_{\mathrm{C}}=\frac{-\Delta \mathrm{H}^{\circ}}{\mathrm{RT}}+\frac{\Delta \mathrm{S}^{\circ}}{\mathrm{R}}
$$

Therefore, the value of standard enthalpy change $\left(\Delta \mathrm{H}^{\circ}\right)$ and standard entropy change $\left(\Delta \mathrm{S}^{\mathrm{o}}\right)$ for the adsorption cycle is determined from the slope and intercept of the ln Kc vs. 1/T plot also, $\mathrm{E}_{\mathrm{a}}$ was calculated from Arrhenius plot intercept (Figures 19 and 20). The thermodynamic parameter's value of $\Delta \mathrm{H}^{\circ}$ has a positive value indicating that the reaction has an endothermic nature in adsorption processes, while $\Delta \mathrm{G}^{\circ}$ has a negative value that indicates the reaction is spontaneous (Table 4). As the negativity of $\Delta \mathrm{G}^{\circ}$ increased with increasing temperature, it confirms that the "favorability" increases with temperature [57,58].
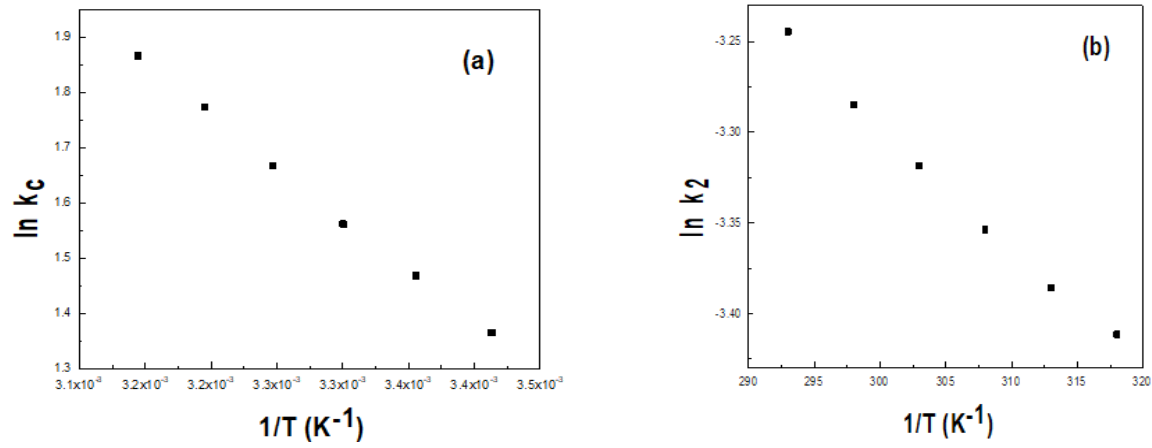

Figure 19. (a) Van't Hoff plots for AR57 adsorption onto the PMNs adsorbent; (b) Arrhenius plots for AR57 adsorption onto the PMNs adsorbent.
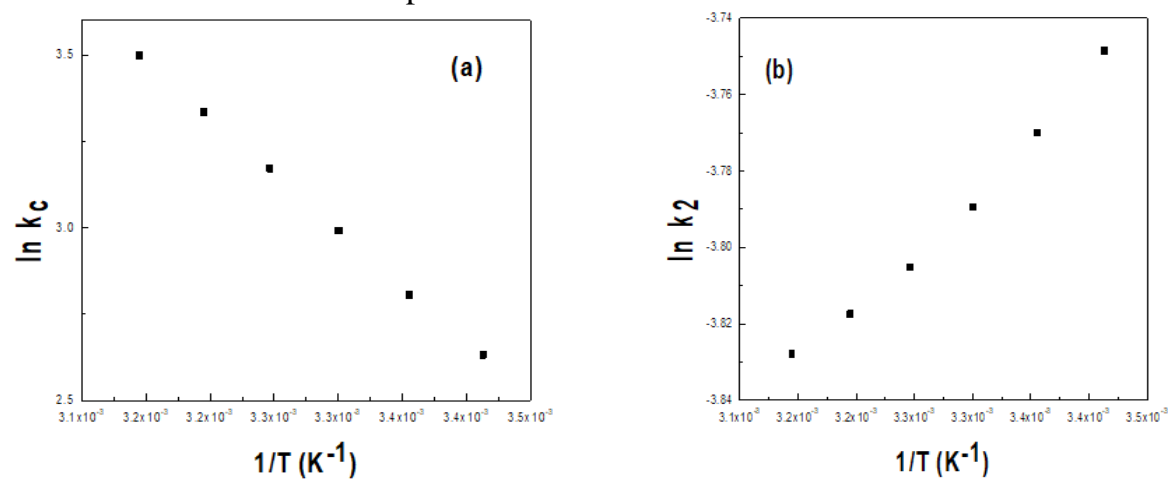

\begin{tabular}{|c|c|c|c|c|c|c|c|c|}
\hline \multirow[t]{2}{*}{$\Delta \mathbf{H}^{\mathbf{0}}\left(\mathrm{kJ} \mathrm{mol}^{-1}\right)$} & \multirow[t]{2}{*}{$\Delta \mathbf{S}^{\mathbf{o}}\left(\mathrm{J} \mathrm{mol}^{-1} \mathbf{K}^{-1}\right)$} & \multirow[t]{2}{*}{$\mathrm{Ea}\left(\mathrm{kJ} \mathrm{mol}^{-1}\right)$} & \multirow[t]{2}{*}{$\mathbf{T}_{0}(\mathbf{K})$} & \multicolumn{5}{|c|}{$\Delta \mathbf{G}^{\mathbf{0}}\left(\mathrm{kJ} \mathrm{mol}^{-1}\right)$} \\
\hline & & & & 298 & 303 & 308 & 313 & 318 \\
\hline 27.01 & 114 & 2.46 & 237 & -6.39 & -6.96 & -7.5 & -8.1 & -9.3 \\
\hline
\end{tabular}

Figure 20. (a) Van't Hoff plots for RR adsorption onto the PMNs adsorbent; (b) Arrhenius plots for RR adsorption onto the PMNs adsorbent.

Table 4. Standard enthalpy, entropy, and free energy changes for AR57 and RR adsorption on PMNs. 
In industries and water purification plants, the maximum temperature at which the adsorption is highly feasible and spontaneous is important. The adsorption of AR57 and RR on surfaces with PMNs can be either spontaneous or non-spontaneous, depending on temperature. The maximum temperature value that coincides with a null value of standard free energy can be inferred from Eq. 22. The temperature variety can be calculated by the temperature value at which the normal free energy for adsorption processes is zero $\left(\mathrm{T}_{0}\right)$. Then, the minimum temperature is random.

$$
\mathrm{T}_{0}=\frac{\Delta \mathrm{H}^{\circ}}{\Delta \mathrm{S}^{\circ}}
$$

In this case, the calculated value for AR57 and RR of zero standard free energy temperature ( $\left.\mathrm{T}_{0}\right)$ is 242 and $237 \mathrm{~K}$, respectively. The low $\mathrm{T}_{0}$ values indicate the viability of the adsorbents studied, which remove both colorants at very low temperatures

\subsubsection{Effect of ionic strength (addition of $\mathrm{NaCl}$ ).}

The effect of chloride ions on extracting Acid Red 57 and Remazol Red was investigated by adding concentration $\mathrm{NaCl}$ (from 10 to $40 \mathrm{~g} / \mathrm{L} \mathrm{C} 0: 1.83 \times 10^{-4} \mathrm{molL}^{-1}$; sorbent dosage: $0.02 \mathrm{~g} / 25 \mathrm{~mL})$ for AR57 while for RR $\left(\mathrm{C}_{0}: 1.51 \times 10^{-4} \mathrm{molL}^{-1}\right.$; sorbent dosage: 0.02 $\mathrm{g} / 25 \mathrm{~mL})$.

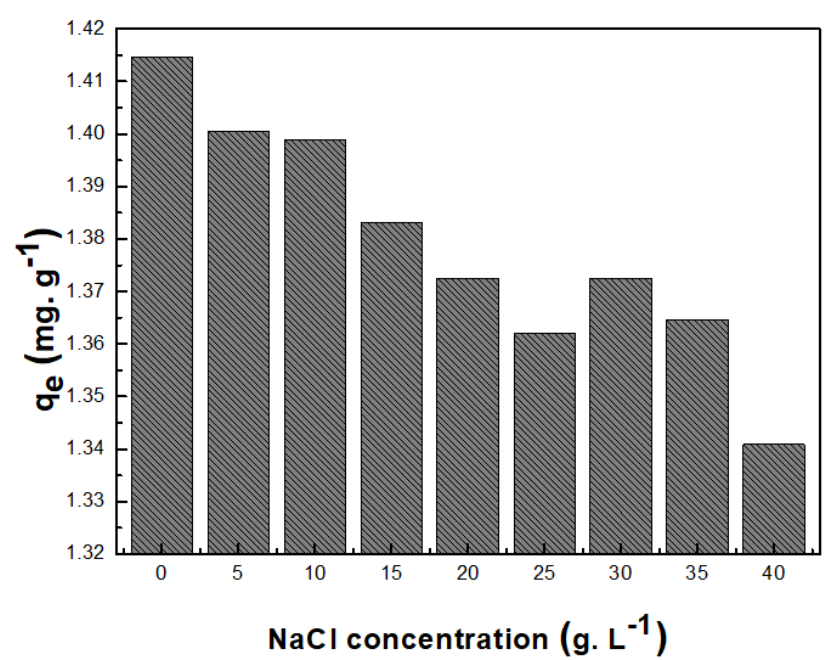

Figure 21. Influence of $\mathrm{NaCl}$ on $\mathrm{AR} 57$ adsorption onto the PMNs adsorbent $\left(\mathrm{C}_{0}: 1.83 \times 10^{-4} \mathrm{molL}^{-1}\right.$; initial $\mathrm{pH} 3$;

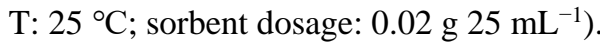

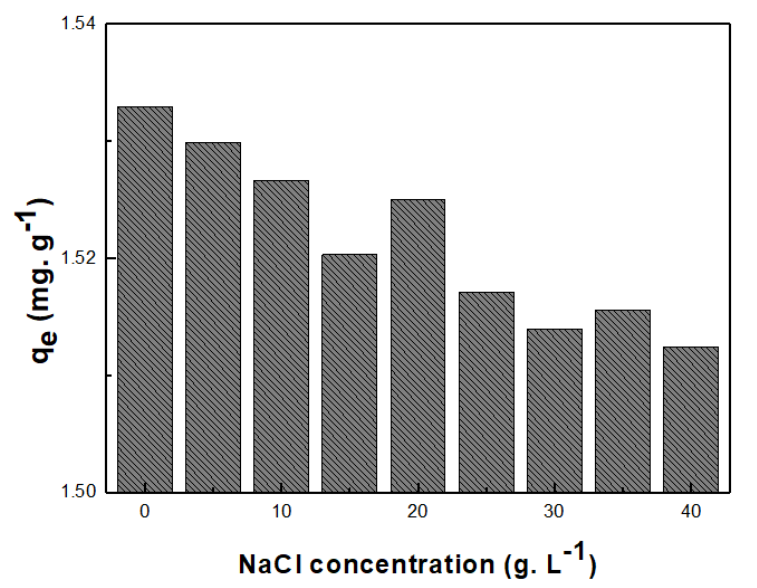

Figure 22. Influence of $\mathrm{NaCl}$ on $\mathrm{RR}$ adsorption onto the $\mathrm{PMNs}$ adsorbent $\left(\mathrm{C}_{0}: 1.51 \times 10^{-4} \mathrm{molL}^{-1}\right.$; initial $\mathrm{pH} 4$; $\mathrm{T}: 25^{\circ} \mathrm{C}$; sorbent dosage: $0.02 \mathrm{~g} 25 \mathrm{~mL}^{-1}$ ). 
The sorption efficiency is slightly reduced for the considered adsorbents increasing the amount of $\mathrm{NaCl}$. Sorption capability reduction of about $20 \%$, when sodium chloride concentration is $20 \mathrm{~g} / \mathrm{L}$, was expected. This is possibly due to chloride anions' competitive effect on the AR57 and RR anions to interact with the sorption sites [59]. Interestingly, even if the concentration of $\mathrm{NaCl}$ is $40 \mathrm{~g}$. $\mathrm{L}-1$, the decrease in adsorption efficiency decreases by $1.5 \%$, which means the potential is retained even under extreme conditions (Figures 21 and 22).

\subsubsection{Comparison with other adsorbents.}

A comparison was made and presented in Tables 5 and 6 of the maximum AR57 and RR adsorption capacities using PMNs as an adsorbent with that of the other adsorbents previously mentioned. This indicates that PMNs have a high potential of adsorption for both AR57 and RR.

Table 5. Adsorption capacity $\left(\mathrm{q}_{\mathrm{m}}\right)$ of various adsorbents for the AR57 dye.

\begin{tabular}{l|l|c} 
Adsorbent & $\mathbf{Q} \mathbf{m}\left(\mathbf{m g g}^{-\mathbf{1}}\right)$ & Reference \\
\hline Surfactant-modified sepiolite & 425 & {$[60]$} \\
\hline Sepiolite & 134.6 & {$[61]$} \\
\hline HTAB-modified sepiolite & 307.4 & {$[62]$} \\
\hline Acid activated bentonite & 416.3 & {$[63]$} \\
\hline PMNs & 888.68 & This work
\end{tabular}

Table 6. Adsorption capacity $\left(\mathrm{q}_{\mathrm{m}}\right)$ of various adsorbents for the RR dye.

\begin{tabular}{l|l|l} 
Adsorbent & $\mathbf{Q m}\left(\mathbf{m g g}^{-\mathbf{1}}\right)$ & Reference \\
\hline Chiston & 182.18 & {$[64]$} \\
\hline Rice husk ash & 0.86 & {$[65]$} \\
\hline $\mathrm{NH}_{2}$-MCM-41 & 50.4 & {$[66]$} \\
\hline Pistachio shell & 108.15 & {$[67]$} \\
\hline Saw Dust & 2.73 & {$[68]$} \\
\hline PMNs & 808.43 & This work
\end{tabular}

\subsection{Desorption studies.}

A significant property is the reusability of adsorbent devices such as PMNs for implemented applications. Our work now relates to the adsorption efficiency of PMNs for three consecutive adsorption-desorption sequences. The regeneration of the examined sorbent PMNs (the adsorbent charged by AR57 and RR) was achieved by injecting $0.02 \mathrm{~g}$ of PMNs into the container and washed carefully afterward by flowing several times using $0.01 \mathrm{M} \mathrm{HCl}$ until $\mathrm{pH}$ reaches 7 , then washed several times with distilled water. The remaining amount of coloring was substituted with ethanol. The adsorbent was collected and put in the oven for 4 hours at $60^{\circ} \mathrm{C}$.

After regeneration, the adsorbent ready for the second run of uptake. The separation efficiency of the regeneration of adsorption/desorption processes was the full adsorbent for the 2nd run of uptake after regeneration [69]. Regeneration efficiency was found to be 98.2, 94.5, $90.1 \%$ for the separate adsorption/desorption process. For AR57 and 97.2, 95.6, $92 \%$ for RR (Eq. 23). It can be due to the blocking of adsorption pages with PMNs. Also characterized XRD of the material of PMNs after three-cycle research and found that the crystallinity and structure were the same 
This result shows that PMNs are highly productive and still serve more than 90 percent of the original potential after the third sprint and excellent magnetic separation efficiency Figure 23.

The efficiency of regeneration was calculated using the following equation:

$$
\text { Regeneration efficiency }(\%)=\frac{\text { Total adsorption capacity in the second run }}{\text { Total adsorption capacity in the first run }} \times 100
$$

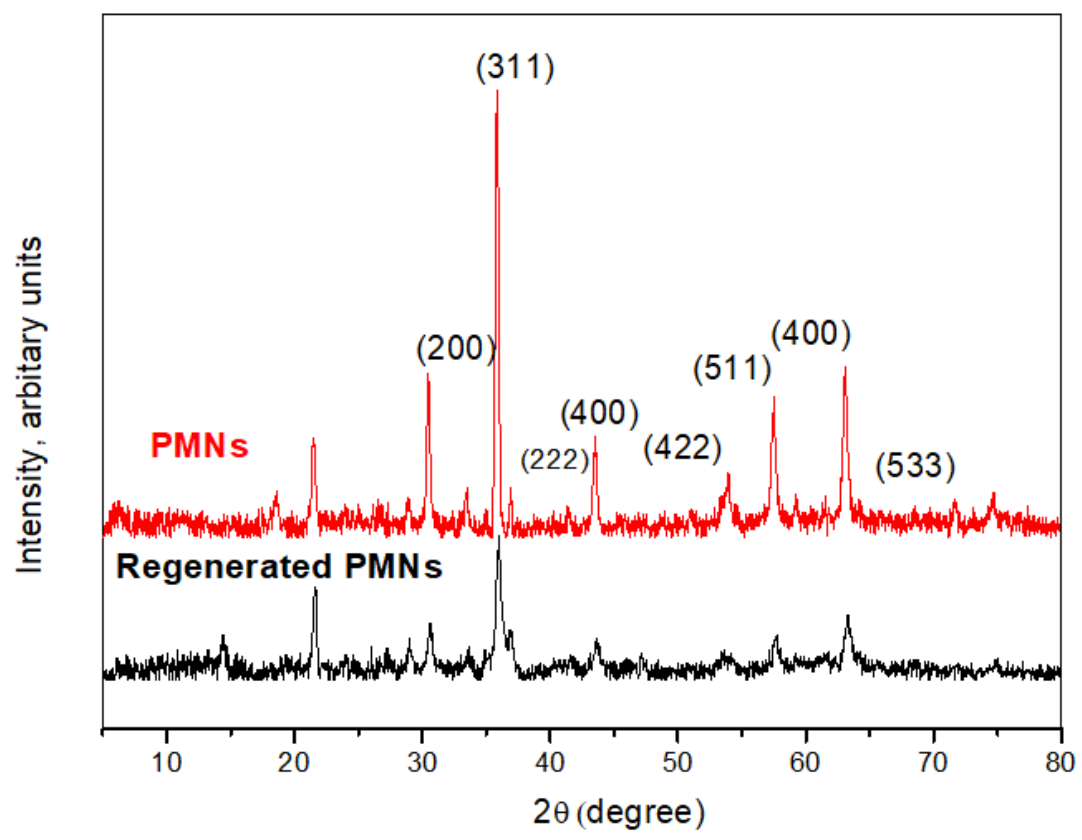

Figure 23. X-ray diffraction spectra of PMNs and PMNs regenerated.

\section{Conclusions}

To sum up, nanospheres of Porous magnetite $\mathrm{Fe}_{3} \mathrm{O}_{4}$ (PMNs) have been successfully synthesized. They have proven to be a high-efficiency adsorbent. The morphology of the PMNs is very uniform in a spherical shape, with an average particle size of $\sim 25,84 \mathrm{~nm}$ in diameter. The contents of PMNs have a relatively high BET surface area of $143.65 \mathrm{~m}^{2} \mathrm{~g}^{-1}$ and an average pore size of $2.24 \mathrm{~nm}$, which is helpful for adsorption. Results suggested that AR57 and RR adsorption was highly dependent on initial dye concentration, initial solution $\mathrm{pH}$, contact time, and temperature. The adsorption equilibrium showed that the Langmuir isotherm is a better fit of the experimental data than the other versions for both AR57 and RR dyes. The mean adsorption energy $\left(E_{a}\right)$ is 20.24 and $31.3 \mathrm{kJmol}^{-1}$ for AR57 and RR, respectively, suggesting the chemisorption method. The pseudo-second-order kinetic model, based on the correlation coefficient $\left(\mathrm{R}^{2}\right)$, was found to follow the adsorption kinetics. The determined thermodynamic parameters $\left(\Delta \mathrm{H}^{\mathrm{o}}, \Delta \mathrm{S}^{\mathrm{o}}\right.$, and $\left.\Delta \mathrm{G}^{\mathrm{o}}\right)$ showed that, under the experimental conditions, the adsorption of both dyes on PMNs was spontaneous and endothermic. PMNs have strong reusability characteristics due to their high efficiency since they still serve more than $90 \%$ after the third run of the initial capacity and excellent magnetic separation efficiency. It is expected that PMNs, which feature well-defined standard mesopores, high surface area, and crystalline frameworks, provide great potential for different types of applications.

\section{Funding}

This research received no external funding. 


\section{Acknowledgment}

This research has no acknowledgment.

\section{Conflicts of Interest}

The authors declare that they have no known competing financial interests or personal relationships that could have influenced the work reported in this paper.

\section{References}

1. Martínez-Huitle, C.A.; Rodrigo, M.A.; Sirés, I.; Scialdone, O. Single and Coupled Electrochemical Processes and Reactors for the Abatement of Organic Water Pollutants: A Critical Review. Chem. Rev. 2015, 115, 13362-13407, https://doi.org/10.1021/acs.chemrev.5b00361.

2. Robinson, T.; Chandran, B.; Nigam, P. Effect of pretreatments of three waste residues, wheat straw, corncobs and barley husks on dye adsorption. Bioresour. Technol. 2002, 85, 119-124, https://doi.org/10.1016/S09608524(02)00099-8.

3. Vo, T.K.; Nguyen, V.C.; Quang, D.T.; Park, B.J.; Kim, J. Formation of structural defects within UiO-66(Zr)$(\mathrm{OH}) 2$ framework for enhanced $\mathrm{CO} 2$ adsorption using a microwave-assisted continuous-flow tubular reactor. Microporous Mesoporous Mater. 2021, 312, 110746, https://doi.org/10.1016/j.micromeso.2020.110746.

4. Lei, G.; Li, Q.; Liu, H.; Zhang, Y. Selective adsorption of $\mathrm{CO}_{2}$ by Hex-star phosphorene from natural gas: Combining molecular simulation and real adsorbed solution theory. Chem. Eng. Sci. 2021, 231, 116283, https://doi.org/10.1016/j.ces.2020.116283.

5. Dehbi, A.; Dehmani, Y.; Omari, H.; Lammini, A.; Elazhari, K.; Abdallaoui, A. Hematite Iron Oxide Nanoparticles $\left(\alpha-\mathrm{Fe}_{2} \mathrm{O}_{3}\right)$ : Synthesis and Modelling Adsorption of Malachite Green. Journal of Environmental Chemical Engineering 2019, 8, 103394, https://doi.org/10.1016/j.jece.2019.103394.

6. Aragaw, T.A. Recovery of iron hydroxides from electro-coagulated sludge for adsorption removals of dye wastewater: Adsorption capacity and adsorbent characteristics. Surfaces and Interfaces 2020, 18, 100439, https://doi.org/10.1016/j.surfin.2020.100439.

7. Kumar, A.; Ropital, F.; de Bruin, T.; Diawara, B. Effects of surface orientations of $\mathrm{Cr}_{2} \mathrm{O}_{3}$ on $\mathrm{CO}_{2}$ adsorption: A DFT approach. Appl. Surf. Sci. 2020, 529, 147127, https://doi.org/10.1016/j.apsusc.2020.147127.

8. Zhao, D.; Timmons, D.J.; Yuan, D.; Zhou, H.-C. Tuning the Topology and Functionality of Metal-Organic Frameworks by Ligand Design. Acc. Chem. Res. 2011, 44, 123-133, https://doi.org/10.1021/ar100112y.

9. Bemani, A.; Baghban, A.; Mohammadi, A.H.; Andersen, P.Ø. Estimation of adsorption capacity of $\mathrm{CO}_{2}, \mathrm{CH}_{4}$, and their binary mixtures in Quidam shale using LSSVM: Application in $\mathrm{CO}_{2}$ enhanced shale gas recovery and $\mathrm{CO}_{2}$ storage. Journal of Natural Gas Science and Engineering 2020, 76, 103204, https://doi.org/10.1016/j.jngse.2020.103204.

10. Droepenu, E.K.; Asare, E.A.; Dampare, S.B.; Adotey, D.K.; Gyampoh, A.O.; Kumi-Arhin, E.J.B.R.i.A.C. Laboratory and Commercial Synthesized Zinc Oxide Nanoparticles Adsorption onto Coconut Husk: Characterization, Isotherm, Kinetic, and Thermodynamic Studies. Biointerface Research in Applied Chemistry 2021, 11, 7871-7889, https://doi.org/10.33263/BRIAC111.78717889.

11. Papa, E.; Landi, E.; Natali Murri, A.; Miccio, F.; Vaccari, A.; Medri, V. $\mathrm{CO}_{2}$ adsorption at intermediate and low temperature by geopolymer-hydrotalcite composites. Open Ceramics 2021, 5, 100048, https://doi.org/10.1016/j.oceram.2020.100048.

12. Bandosz, T.J.; Petit, C. MOF/graphite oxide hybrid materials: exploring the new concept of adsorbents and catalysts. Adsorption 2011, 17, 5-16, https://doi.org/10.1007/s10450-010-9267-5.

13. Zhang, S.; Du, Z.; Li, G. Metal-organic framework-199/graphite oxide hybrid composites coated solid-phase microextraction fibers coupled with gas chromatography for determination of organochlorine pesticides from complicated samples. Talanta 2013, 115, 32-39, https://doi.org/10.1016/j.talanta.2013.04.029

14. Taran, M.; Safaei, M.; Karimi, N.; Almasi, A. Benefits and Application of Nanotechnology in Environmental Science: an Overview. 2020, https://doi.org/10.33263/BRIAC111.78607870.

15. Ke, F.; Yuan, Y.-P.; Qiu, L.-G.; Shen, Y.-H.; Xie, A.-J.; Zhu, J.-F.; Tian, X.-Y.; Zhang, L.-D. Facile fabrication of magnetic metal-organic framework nanocomposites for potential targeted drug delivery. $J$. Mater. Chem. 2011, 21, 3843-3848, https://doi.org/10.1039/C0JM01770A. 
16. Mandal, P.; Nath, K.K.; Saha, M. Efficient Blue Luminescent Graphene Quantum Dots and their Photocatalytic Ability Under Visible Light. Biointerface Res. Appl. Chem 2021, 11, 8171-8178, https://doi.org/10.33263/BRIAC111.81718178.

17. Mahmoodi, N.M.; Khorramfar, S.; Najafi, F. Amine-functionalized silica nanoparticle: Preparation, characterization and anionic dye removal ability. Desalination 2011, 279, 61-68, https://doi.org/10.1016/j.desal.2011.05.059.

18. Kulkarni, D.; Wachs, I.E. Isopropanol oxidation by pure metal oxide catalysts: number of active surface sites and turnover frequencies. Applied Catalysis A: General 2002, 237, 121-137, https://doi.org/10.1016/S0926860X(02)00325-3.

19. Huang, F.; Xu, Y.; Liao, S.; Yang, D.; Hsieh, Y.-L.; Wei, Q. Preparation of amidoxime polyacrylonitrile chelating nanofibers and their application for adsorption of metal ions. Materials 2013, 6, 969-980, https://doi.org/10.3390/ma6030969.

20. Wang, L.; Wang, A. Adsorption properties of Congo Red from aqueous solution onto surfactant-modified montmorillonite. J. Hazard. Mater. 2008, 160, 173-180, https://doi.org/10.1016/j.jhazmat.2008.02.104.

21. Sun, L.; Zhan, L.; Shi, Y.; Chu, L.; Ge, G.; He, Z. Microemulsion synthesis and electromagnetic wave absorption properties of monodispersed Fe3O4/polyaniline core-shell nanocomposites. Synth. Met. 2014, 187, 102-107, https://doi.org/10.1016/j.synthmet.2013.11.007.

22. Foroughi, F.; Hassanzadeh-Tabrizi, S.A.; Bigham, A. In situ microemulsion synthesis of hydroxyapatite$\mathrm{MgFe} 2 \mathrm{O} 4$ nanocomposite as a magnetic drug delivery system. Materials Science and Engineering: C 2016, 68, 774-779, https://doi.org/10.1016/j.msec.2016.07.028.

23. Hassan, N.; Shahat, A.; El-Didamony, A.; El-Desouky, M.; El-Bindary, A.A. Equilibrium, Kinetic and Thermodynamic studies of adsorption of cationic dyes from aqueous solution using ZIF-8. Moroccan Journal of Chemistry 2020, 8, 8-3, https://doi.org/10.48317/IMIST.PRSM/morjchem-v8i3.21127.

24. Abdelhamid, H.N. Biointerface between ZIF-8 and biomolecules and their applications. Biointerface Res. Appl. Chem. 2021, 11, 8283-8297, https://doi.org/10.33263/BRIAC111.82838297.

25. Lemine, O.M.; Omri, K.; Zhang, B.; El Mir, L.; Sajieddine, M.; Alyamani, A.; Bououdina, M. Sol-gel synthesis of $8 \mathrm{~nm}$ magnetite (Fe3O4) nanoparticles and their magnetic properties. Superlattices Microstruct. 2012, 52, 793-799, https://doi.org/10.1016/j.spmi.2012.07.009.

26. Li, C.; Wei, Y.; Liivat, A.; Zhu, Y.; Zhu, J. Microwave-solvothermal synthesis of Fe3O4 magnetic nanoparticles. Mater. Lett. 2013, 107, 23-26, https://doi.org/10.1016/j.matlet.2013.05.117.

27. Venna, S.R.; Jasinski, J.B.; Carreon, M.A. Structural Evolution of Zeolitic Imidazolate Framework-8. J. Am. Chem. Soc. 2010, 132, 18030-18033, https://doi.org/10.1021/ja109268m.

28. Hassan, N.; Shahat, A.; El-Didamony, A.; El-Desouky, M.G.; El-Bindary, A.A. Synthesis and characterization of $\mathrm{ZnO}$ nanoparticles via zeolitic imidazolate framework-8 and its application for removal of dyes. J. Mol. Struct. 2020, 1210, 128029, https://doi.org/10.1016/j.molstruc.2020.128029.

29. Feng, Y.; Li, Y.; Xu, M.; Liu, S.; Yao, J. Fast adsorption of methyl blue on zeolitic imidazolate framework8 and its adsorption mechanism. RSC Advances 2016, 6, 109608-109612, https://doi.org/10.1039/C6RA23870J.

30. Hassan, N.; El-Sonbati, A.Z.; El-Desouky, M.G. Synthesis, characterization, molecular docking and DNA binding studies of $\mathrm{Cu}(\mathrm{II}), \mathrm{Ni}(\mathrm{II}), \mathrm{Zn}(\mathrm{II})$ and $\mathrm{Mn}(\mathrm{II})$ complexes. J. Mol. Liq. 2017, 242, 293-307, http://dx.doi.org/10.1016/j.molliq.2017.07.019.

31. Chan, L.S.; Cheung, W.H.; Allen, S.J.; McKay, G. Error Analysis of Adsorption Isotherm Models for Acid Dyes onto Bamboo Derived Activated Carbon. Chin. J. Chem. Eng. 2012, 20, 535-542, https://doi.org/10.1016/S1004-9541(11)60216-4.

32. Özacar, M.; Şengil, İ.A. Adsorption of reactive dyes on calcined alunite from aqueous solutions. J. Hazard. Mater. 2003, 98, 211-224, https://doi.org//10.1016/s0304-3894(02)00358-8.

33. Al-Degs, Y.; El-Barghouthi, M.; El-Sheikh, A.; Walker, G. Effect of solution pH, ionic strength, and temperature on adsorption behavior of reactive dyes on activated carbon. Dyes and Pigments 2008, 77, 1623, https://doi.org/10.1016/j.dyepig.2007.03.001.

34. Dahri, M.K.; Kooh, M.R.R.; Lim, L.B.L. Application of Casuarina equisetifolia needle for the removal of methylene blue and malachite green dyes from aqueous solution. Alexandria Engineering Journal 2015, 54, 1253-1263, https://doi.org/10.1016/j.aej.2015.07.005.

35. Özcan, A.S.; Özcan, A. Adsorption of acid dyes from aqueous solutions onto acid-activated bentonite. $J$. Colloid Interface Sci. 2004, 276, 39-46, https://doi.org/10.1016/j.jcis.2004.03.043. 
36. Du, X.; Cheng, Y.; Liu, Z.; Hou, Z.; Wu, T.; Lei, R.; Shu, C. Study on the adsorption of $\mathrm{CH}_{4}, \mathrm{CO}_{2}$ and various $\mathrm{CH}_{4} / \mathrm{CO}_{2}$ mixture gases on shale. Alexandria Engineering Journal 2020, 59, 5165-5178, https://doi.org/10.1016/j.aej.2020.09.046.

37. Hassan, N.; Shahat, A.; El-Didamony, A.; El-Desouky, M.G.; El-Bindary, A.A. Mesoporous iron oxide nano spheres for capturing organic dyes from water sources. J. Mol. Struct. 2020, 1217, 128361, https://doi.org/10.1016/j.molstruc.2020.128361.

38. Ahmad, P.R.; Kumar, R. Adsorption Studies of Hazardous Malachite Green onto Treated Ginger Waste. J. Environ. Manage. 2010, 91, 1032-1038, https://doi.org/10.1016/j.jenvman.2009.12.016.

39. Huang, C.-L.; Wang, P.-Y.; Li, Y.-Y. Fabrication of electrospun $\mathrm{CO}_{2}$ adsorption membrane for zinc-air battery application. Chem. Eng. J. 2020, 395, 125031, https://doi.org/10.1016/j.cej.2020.125031, https://doi.org/10.1016/j.cej.2020.125031.

40. Du, X.; Cheng, Y.; Liu, Z.; Yin, H.; Wu, T.; Huo, L.; Shu, C. $\mathrm{CO}_{2}$ and CH4 adsorption on different rank coals: A thermodynamics study of surface potential, Gibbs free energy change and entropy loss. Fuel 2021, 283, 118886, https://doi.org/10.1016/j.fuel.2020.118886.

41. Langmuir, I. The constitution and fundamental properties of solids and liquids. II. Liquids. J. Am. Chem. Soc. 1917, 39, 1848-1906, https://doi.org/10.1021/ja02254a006.

42. Freundlich, H.; Heller, W. The Adsorption of cis- and trans-Azobenzene. J. Am. Chem. Soc. 1939, 61, 22282230, https://doi.org/10.1021/ja01877a071.

43. Dubinin, M.M.; Zaverina, E.D.; Radushkevich, L.V. Sorption and structure of active carbons. I. Adsorption of organic vapors. Zh. Fiz. Khim. 1947, 21, 151-162.

44. Temkin, M.I. Kinetics of ammonia synthesis on promoted iron catalysts. Acta physiochim. URSS 1940, 12, 327-356.

45. Droepenu, E.K.; Asare, E.A.; Dampare, S.B.; Adotey, D.K.; Gyampoh, A.O.; Kumi-Arhin, E. Laboratory and Commercial Synthesized Zinc Oxide Nanoparticles Adsorption onto Coconut Husk: Characterization, Isotherm, Kinetic, and Thermodynamic Studies. Biointerface Research in Applied Chemistry 2021, 11, 78717889, https://doi.org/10.33263/BRIAC111.78717889.

46. Temkin, M.J.; Pyzhev, V. Recent modifications to Langmuir isotherms. 1940.

47. Petrovic, B.; Gorbounov, M.; Masoudi Soltani, S. Influence of surface modification on selective $\mathrm{CO}_{2}$ adsorption: A technical review on mechanisms and methods. Microporous Mesoporous Mater. 2021, 312 , 110751, https://doi.org/10.1016/j.micromeso.2020.110751.

48. Ayawei, N.; Ekubo, A.T.; Wankasi, D.; Dikio, E.D. Adsorption of congo red by Ni/Al- $\mathrm{CO}_{3}$ : equilibrium, thermodynamic and kinetic studies. Oriental Journal of Chemistry 2015, 31, 1307-1318, http://dx.doi.org/10.13005/ojc/310307.

49. Wedler, C.; Span, R. A pore-structure dependent kinetic adsorption model for consideration in char conversion - Adsorption kinetics of $\mathrm{CO}_{2}$ on biomass chars. Chem. Eng. Sci. 2021, 231, 116281, https://doi.org/10.1016/j.ces.2020.116281.

50. Israel, U.; Eduok, U.M. Biosorption of zinc from aqueous solution using coconut (Cocos nucifera L) coir dust. Archives of Applied Science Research 2012, 4, 809-819.

51. Ho, Y.S.; McKay, G. Sorption of dye from aqueous solution by peat. Chem. Eng. J. 1998, 70, 115-124, https://doi.org/10.1016/S0923-0467(98)00076-1.

52. Abdelhamid, H.N. Biointerface between ZIF-8 and biomolecules and their applications. Biointerface Res. Appl. Chem. 2021, 11, 8283-8297, https://doi.org/10.33263/BRIAC111.82838297.

53. Vijayaraghavan, K. Biosorption of lanthanide (praseodymium) using Ulva lactuca: Mechanistic study and application of two, three, four and five parameter isotherm models. Journal of Environment \& Biotechnology Research 2015, 1, 10-17.

54. Gubernak, M.; Zapala, W.; Tyrpien, K.; Kaczmarski, K. Analysis of Amylbenzene Adsorption Equilibria on Different RP-HPLC. J. Chromatogr. Sci. 2004, 42, 457-463, https://doi.org/10.1093/chromsci/42.9.457.

55. Zhang, Y.; Huang, G.; An, C.; Xin, X.; Liu, X.; Raman, M.; Yao, Y.; Wang, W.; Doble, M. Transport of anionic azo dyes from aqueous solution to gemini surfactant-modified wheat bran: Synchrotron infrared, molecular interaction and adsorption studies. Sci. Total Environ. 2017, 595, 723-732, https://doi.org/10.1016/j.scitotenv.2017.04.031.

56. Juang, R.S.; Wu, F.C.; Tseng, R.L. The Ability of Activated Clay for the Adsorption of Dyes from Aqueous Solutions. Environ. Technol. 1997, 18, 525-531, https://doi.org/10.1023/A:1021585413857.

57. Nollet, H.; Roels, M.; Lutgen, P.; Van der Meeren, P.; Verstraete, W. Removal of PCBs from wastewater using fly ash. Chemosphere 2003, 53, 655-665, https://doi.org/10.1016/S0045-6535(03)00517-4. 
58. Yang, K.; Zhu, L.; Xing, B. Sorption of phenanthrene by nanosized alumina coated with sequentially extracted humic acids. Environmental Science and Pollution Research 2010, 17, 410-419, https://doi.org/10.1007/s11356-009-0163-z.

59. Prasad, C.; Karlapudi, S.; Venkateswarlu, P.; Bahadur, I.; Kumar, S. Green arbitrated synthesis of Fe3O4 magnetic nanoparticles with nanorod structure from pomegranate leaves and Congo red dye degradation studies for water treatment. J. Mol. Liq. 2017, 240, 322-328, https://doi.org/10.1016/j.molliq.2017.05.100.

60. Özcan, A.; Özcan, A.S. Adsorption of Acid Red 57 from aqueous solutions onto surfactant-modified sepiolite. J. Hazard. Mater. 2005, 125, 252-259, https://doi.org/10.1016/j.jhazmat.2005.05.039.

61. Özcan, A.S.; Tetik, Ş.; Özcan, A. Adsorption of Acid Dyes from Aqueous Solutions onto Sepiolite. Sep. Sci. Technol. 2005, 39, 301-320, https://doi.org/10.1081/SS-120027560.

62. Karataş, D.; Senol-Arslan, D.; Ozdemir, O. Experimental and atomic modeling of the adsorption of acid azo dye 57 to sepiolite. Clays Clay Miner. 2018, 66, 426-437, https://doi.org/10.1346/CCMN.2018.064109.

63. Boparai, H.K.; Joseph, M.; O’Carroll, D.M. Kinetics and thermodynamics of cadmium ion removal by adsorption onto nano zerovalent iron particles. J. Hazard. Mater. 2011, 186, 458-465, https://doi.org/10.1016/j.jhazmat.2010.11.029.

64. Kabir, M.P.; Islam, M.M.; Masum, S.M.; Hossain, M.M. Adsorption of remazol red RR onto chitosan from aqueous solution. Bangladesh Journal of Scientific and Industrial Research 2014, 49, 111-118, https://doi.org/10.3329/bjsir.v49i2.22005.

65. Costa, J.A.S.; Paranhos, C.M. Evaluation of rice husk ash in adsorption of Remazol Red dye from aqueous media. SN Applied Sciences 2019, 1, 397, https://doi.org/10.1007/s42452-019-0436-1.

66. Santos, D.O.; de Lourdes Nascimento Santos, M.; Costa, J.A.S.; de Jesus, R.A.; Navickiene, S.; Sussuchi, E.M.; de Mesquita, M.E. Investigating the potential of functionalized MCM-41 on adsorption of Remazol Red dye. Environmental Science and Pollution Research 2013, 20, 5028-5035, https://doi.org/10.1007/s11356-012-1346-6.

67. Armagan, B.; Toprak, F. Using pistachio shell for Remazol Red removal from aqueous solutions: equilibrium, kinetics and thermodynamics. Desalination and Water Treatment 2015, 56, 136-145, https://doi.org/10.1080/19443994.2014.934719.

68. Ara, N.J.; Hasan, M.A.; Rahman, M.A.; Salam, M.A.; Salam, A.; Alam, A.M.S. Removal of remazol red from textile waste water using treated sawdust-an effective way of effluent treatment. Bangladesh Pharmaceutical Journal 2013, 16, 93-98, https://doi.org/10.3329/bpj.v16i1.14501.

69. Liu, J.; Yu, H.; Liang, Q.; Liu, Y.; Shen, J.; Bai, Q. Preparation of polyhedral oligomeric silsesquioxane based cross-linked inorganic-organic nanohybrid as adsorbent for selective removal of acidic dyes from aqueous solution. J. Colloid Interface Sci. 2017, 497, 402-412, https://doi.org/10.1016/j.jcis.2017.03.028. 